\title{
Intercomparing Shortwave Radiation Codes for Climate Studies
}

\author{
Y. Fouquart AND B. BONNEL \\ Laboratoire d'Optique Atmospherique, Villeneuve d'Ascq, France
}

\section{RAMASWAMY}

\author{
NOAA Geophysical Fluid Dynamics Laboratory, Princeton University, Princeton, New Jersey
}

\begin{abstract}
As a second step of the international program of Intercomparison of Radiation Codes Used in Climate Models (ICRCCM), an intercomparison of shortwave radiation models was initiated. Among the 26 codes that participated in the comparison were very detailed (line-by-line), narrow-band (high-spectral resolution), as well as highly parameterized (low-spectral resolution) models. A considerable spread was detected in the response of these models to a set of well-defined atmospheric profiles. Substantial discrepancies exist among models even for the simplest case of pure water vapor absorption with standard deviation ranging from $1 \%$ to $3 \%$ for the downward fluxes at the surface and from $6 \%$ to $11 \%$ for the total atmospheric absorption. The divergences in downward surface flux increase to nearly $4 \%$ when all absorbers and the molecular scattering are considered. In cloudy conditions the divergences range from $4 \%$ to $10 \%$, depending on the cloud optical thickness. Another major uncertainty that has been identified is the spectral averaging of the scattering properties which can result in very significant errors for low spectral resolution codes. Since these errors appear to be systematic, they may induce unrealistic feedback mechanisms in numerical climate models. The amplitude of the differences between models is in many cases larger than the accuracy required for the achievements of several objectives of the World Climate Research Program. While reference solutions for the absorption and scattering in atmospheres can be obtained based on the state-of-the-art spectroscopic knowiedge and rigorous computational techniques, the absolute tests of the validity of the radiation algorithms would be comprehensive field experiments in which the radiative and all relevant atmospheric parameters are measured to a high degree of accuracy.
\end{abstract}

\section{INTRODUCTION}

Radiation is a primary process governing the general circulation of the atmosphere and is the basic means through which significant changes in the climate may occur. As such, its treatment in climate models requires careful attention. Instead, the idea that radiation is a science with a very well-established physical basis is widespread in the climate community. As a consequence, relatively little attention has been paid until recently to a careful calibration of the various hypotheses, simplifications, or parameterizations on which the radiation codes in climate models are based. It is widely believed that solar radiation is even better understood than the longwave. Indeed, whereas one can find a variety of papers dealing with the calculation of infrared radiative fluxes and cooling rates, from Elsasser [1942] to Harshvardhan et al. [1987], the literature is, by comparison, deficient on the subject of transfer of shortwave radiation. When describing their radiative convective model, Manabe and Strickler [1964] specifically considered the transfer of solar radiation and the influence of clouds. Since then, Lacis and Hansen [1974], Geleyn and Hollingsworth [1979], Fouquart and Bonnel [1980], Hense et al. [1982], and Zdunkowski et al. [1982] have presented other global circulation model (GCM) oriented shortwave codes. Stephens [1984] reviewed the various techniques or parameterizations used in these schemes and compared the results for water vapor absorption from different techniques.

The importance of and the precision required in the radiative fluxes for climate studies need hardly be empha-

Copyright 1991 by the American Geophysical Union.

Paper number 90JD00290.

0148-0227/91/90JD-00290\$05.00 sized: a mere $1 \%$ decrease in solar constant $\left(\sim 14 \mathrm{~W} / \mathrm{m}^{2}\right)$ can yield Ice Age conditions on Earth; a doubling of $\mathrm{CO}_{2}$, which implies a radiative forcing of only $4 \mathrm{~W} / \mathrm{m}^{2}$, may affect the climate substantially, while a change of $10 \mathrm{~W} / \mathrm{m}^{2}$ over a year can be the difference between various climate modes in the coupled ocean-atmosphere system. It is apparent that a radiative inaccuracy of even a few $\mathrm{W} / \mathrm{m}^{2}$ can seriously compromise the evaluation of the diabatic forcing (fluxes and heating rates) of the surface-atmosphere system.

Until recently, no attempt has been made to evaluate the accuracy of the various shortwave radiation codes through a systematic comparison of their results based on a common set of references. Such a comparison was the objective of the Intercomparison of Radiation Codes Used in Climate Models (ICRCCM) study, which was established in 1983 under the auspices of the Joint Scientific Committee for the World Climate Research Program, the U.S. Department of Energy, and the International Radiation Commission of the International Association of Meteorology and Atmospheric Physics (IAMAP). It was also expected that this exercise would generate benchmark or reference solutions for the radiative transfer in model atmospheres. The first stage of the ICRCCM activity focused on clear-sky longwave calculations. The second step considered shortwave intercomparisons in both clear and cloudy conditions. The purpose of this paper is to report on these latter intercomparisons. .

A total of 57 test cases (see Table 1) were selected and distributed among the community. A majority of the cases are for clear-sky conditions (i.e., no clouds). The test cases considered included clear-sky and overcast atmospheres. It was decided at the outset that intercomparisons between the various models for clear skies had to be analyzed and placed 
TABLE 1. Summary of the 57 Solar Cases Selected for the Shortwave Computations

\begin{tabular}{|c|c|c|c|}
\hline \multicolumn{4}{|c|}{ Purely Absorbing Cases: Surface Albedo 0.2} \\
\hline Case & Gases & Atmosphere & Zenith Angle, deg \\
\hline 1 & $\mathrm{H}_{2} \mathrm{O}$ only & mid-latitude summer & 30 \\
\hline 2 & $\mathrm{H}_{2} \mathrm{O}$ only & mid-latitude summer & 75 \\
\hline 3 & $\mathrm{H}, \mathrm{O}$ only & tropical & 30 \\
\hline 4 & $\mathrm{H}_{2} \mathrm{O}$ only & tropical & 75 \\
\hline 5 & $\mathrm{H}_{2} \mathrm{O}$ only & sub-Arctic winter & 30 \\
\hline 6 & $\mathrm{H}_{2} \mathrm{O}$ only & sub-Arctic winter & 75 \\
\hline 7 & $\mathrm{H}_{2} \mathrm{O}, \mathrm{O}_{2}, \mathrm{CO}_{2} 300 \mathrm{ppmv}$ & mid-latitude summer & 30 \\
\hline 8 & $\mathrm{H}_{2} \mathrm{O}, \mathrm{O}_{2}, \mathrm{CO}_{2} 600 \mathrm{ppmv}$ & mid-latitude summer & 30 \\
\hline 9 & $\mathrm{H}_{2} \mathrm{O}, \mathrm{O}_{2}, \mathrm{CO}_{2} 300 \mathrm{ppmv}$ & mid-latitude summer & 75 \\
\hline 10 & $\mathrm{H}_{2} \mathrm{O}, \mathrm{O}_{2}, \mathrm{CO}_{2} 600 \mathrm{ppmv}$ & mid-latitude summer & 75 \\
\hline 11 & $\mathrm{H}_{2} \mathrm{O}, \mathrm{O}_{2}, \mathrm{CO}_{2} 300 \mathrm{ppmv}$ & tropical & 30 \\
\hline 12 & $\mathrm{H}_{2} \mathrm{O}, \mathrm{O}_{2}, \mathrm{CO}_{2} 600 \mathrm{ppmv}$ & tropical & 30 \\
\hline 13 & $\mathrm{H}_{2} \mathrm{O}, \mathrm{O}_{2}, \mathrm{CO}_{2} 300 \mathrm{ppmv}$ & tropical & 75 \\
\hline 14 & $\mathrm{H}_{2} \mathrm{O}, \mathrm{O}_{2}, \mathrm{CO}_{2} 600 \mathrm{ppmv}$ & tropical & 75 \\
\hline 15 & $\mathrm{H}_{2} \mathrm{O}, \mathrm{O}_{2}, \mathrm{CO}_{2} 300 \mathrm{ppmv}$ & sub-Arctic winter & 30 \\
\hline 16 & $\mathrm{H}_{2} \mathrm{O}, \mathrm{O}_{2}, \mathrm{CO}_{2} 600 \mathrm{ppmv}$ & sub-Arctic winter & 30 \\
\hline 17 & $\mathrm{H}_{2} \mathrm{O}, \mathrm{O}_{2}, \mathrm{CO}_{2} 300 \mathrm{ppmv}$ & sub-Arctic winter & 75 \\
\hline 18 & $\mathrm{H}_{2} \mathrm{O}, \mathrm{O}_{2}, \mathrm{CO}_{2} 600 \mathrm{ppmv}$ & sub-Arctic winter & 75 \\
\hline 19 & $\mathrm{H}_{2} \mathrm{O}, \mathrm{O}_{2}, \mathrm{O}_{3}, \mathrm{CO}_{2} 300 \mathrm{ppmv}$ & mid-latitude summer & 30 \\
\hline 20 & $\mathrm{H}_{2} \mathrm{O}, \mathrm{O}_{2}, \mathrm{O}_{3}, \mathrm{CO}_{2} 600 \mathrm{ppmv}$ & mid-latitude summer & 30 \\
\hline 21 & $\mathrm{H}_{2} \mathrm{O}, \mathrm{O}_{2}, \mathrm{O}_{3}, \mathrm{CO}_{2} 300 \mathrm{ppmv}$ & mid-latitude summer & 75 \\
\hline 22 & $\mathrm{H}_{2} \mathrm{O}, \mathrm{O}_{2}, \mathrm{O}_{3}, \mathrm{CO}_{2} 600 \mathrm{ppmv}$ & mid-latitude summer & 75 \\
\hline 23 & $\mathrm{H}_{2} \mathrm{O}, \mathrm{O}_{2}, \mathrm{O}_{3}, \mathrm{CO}_{2} 300 \mathrm{ppmv}$ & tropical & 30 \\
\hline 24 & $\mathrm{H}_{2} \mathrm{O}, \mathrm{O}_{2}, \mathrm{O}_{3}, \mathrm{CO}_{2} 600 \mathrm{ppmv}$ & tropical & 30 \\
\hline 25 & $\mathrm{H}_{2} \mathrm{O}, \mathrm{O}_{2}, \mathrm{O}_{3}, \mathrm{CO}_{2} 300 \mathrm{ppmv}$ & tropical & 75 \\
\hline 26 & $\mathrm{H}_{2} \mathrm{O}, \mathrm{O}_{2}, \mathrm{O}_{3}, \mathrm{CO}_{2} 600 \mathrm{ppmv}$ & tropical & 75 \\
\hline 27 & $\mathrm{H}_{2} \mathrm{O}, \mathrm{O}_{2}, \mathrm{O}_{3}, \mathrm{CO}_{2} 300 \mathrm{ppmv}$ & sub-Arctic winter & 30 \\
\hline 28 & $\mathrm{H}_{2} \mathrm{O}, \mathrm{O}_{2}, \mathrm{O}_{3}, \mathrm{CO}_{2} 600 \mathrm{ppmv}$ & sub-Arctic winter & 30 \\
\hline 29 & $\mathrm{H}_{2} \mathrm{O}, \mathrm{O}_{2}, \mathrm{O}_{3}, \mathrm{CO}_{2} 300 \mathrm{ppmv}$ & sub-Arctic winter & 75 \\
\hline 30 & $\mathrm{H}_{2} \mathrm{O}, \mathrm{O}_{2}, \mathrm{O}_{3}, \mathrm{CO}_{2} 600 \mathrm{ppmv}$ & sub-Arctic winter & 75 \\
\hline
\end{tabular}

Calculations With Scattering and Absorption: All Gases, $\mathrm{CO}_{2} 300 \mathrm{ppmv}$

\begin{tabular}{cclc}
\hline Case & Surface Albedo & \multicolumn{1}{c}{ Atmosphere } & Zenith Angle, deg \\
\hline 31 & 0.2 & mid-latitude summer & 30 \\
32 & 0.8 & mid-latitude summer & 30 \\
33 & 0.2 & mid-latitude summer & 75 \\
34 & 0.8 & mid-latitude summer & 75 \\
35 & 0.2 & tropical & 30 \\
36 & 0.8 & tropical & 30 \\
37 & 0.2 & tropical & 75 \\
38 & 0.8 & tropical & 75 \\
39 & 0.2 & sub-Arctic winter & 30 \\
40 & 0.8 & sub-Arctic winter & 30 \\
41 & 0.2 & sub-Arctic winter & 75 \\
42 & 0.8 & sub-Arctic winter & 75 \\
\hline
\end{tabular}

Calculations With Clouds: All Gases, $\mathrm{CO}_{2} 300$ ppmv, Mid-Latitude Summer, Surface Albedo 0.2, Solar Zenith Angle $30^{\circ}$

\begin{tabular}{lccc}
\hline Case & Cloud Type & Top Height & LWP, g/m \\
\hline 43 & CS & 13 & 10 \\
44 & (cancelled) & & 10 \\
45 & CS & 2 & 10 \\
46 & CL & 13 & 200 \\
47 & CL & 13 & 10 \\
48 & CL & 2 & 200 \\
49 & CL & 2 & \\
\hline
\end{tabular}

Aerosol Scattering and Absorption: Mid-Latitude Summer, All Gases, $\mathrm{CO}_{2} 300 \mathrm{ppmv}$

\begin{tabular}{cccc}
\hline Case & Aerosol Profile & Surface Albedo & Zenith Angle, deg \\
\hline 50 & Maritime I & 0.2 & 30 \\
51 & Maritime I & 0.8 & 30 \\
$' 52$ & Maritime I & 0.2 & 75 \\
53 & Maritime I & 0.8 & 75 \\
54 & Maritime II & 0.2 & 30 \\
55 & Maritime II & 0.8 & 30 \\
56 & Maritime II & 0.2 & 75 \\
57 & Maritime II & 0.8 & 75 \\
\hline \hline
\end{tabular}


TABLE 2. Participants in the ICRCCM Shortwave Study

\begin{tabular}{|c|c|c|c|}
\hline Participant & $\begin{array}{c}\text { Accessible } \\
\text { Climate Model }\end{array}$ & $\begin{array}{l}\text { Model } \\
\text { Type }\end{array}$ & Affiliation \\
\hline B. Briegleb & NCAR, CCM & LR & National Center for Atmospheric Research, USA \\
\hline M.-D. Chou & & LBL, LR & NASA Goddard Space Flight Center, USA \\
\hline J. Fisher, H. Grassl & & HR & Universität Kiel, FRG \\
\hline Y. Fouquart, B. Bonnel & LMD, ECMWF & HR, LR & Laboratoire d'Optique Atmosphérique, France \\
\hline S. Ghan & LLNL & LR & Lawrence Livermore National Laboratory, USA \\
\hline Harshvardhan & GLA & LR & NASA Goddard Space Flight Center, USA \\
\hline I. Karol & & & Main Geophysical Observatory, USSR \\
\hline A. Lacis & GISS & HR & NASA Goddard Institute for Space Studies, USA \\
\hline R. T. Pinker, I. Laszlo & & LR & University of Maryland, USA \\
\hline V. Ramaswamy & GFDL & LBL & GFDL, Princeton University, USA \\
\hline L. Remer & UCLA & LR & University of California, USA \\
\hline L. Rikus & BMRC & LR & Bureau of Meteorological Research Centre, Australia \\
\hline B. Rockel & & $\mathbf{L R}$ & Institut für Geophysik und Meteorologie, FRG \\
\hline M. E. Schlesinger & OSU & LR & Oregon State University, USA \\
\hline J. Schmetz & & HR & European Space Operations Center, FRG \\
\hline E. A. Smith & & HR & Florida State University, USA \\
\hline J. T. Suttles & & $\mathbf{H R}$ & NASA Langley Research Center, USA \\
\hline G. Visconti & & HR & Universitè dell'Aquila, Italy \\
\hline K. R. Vupputuri & AES & HR & Canadian Climate Centre, Canada \\
\hline W.-C. Wang & & HR & $\begin{array}{l}\text { Atmospheric and Environmental Research, Inc., } \\
\text { USA }\end{array}$ \\
\hline R. C. Wilderspin & UK & LR & Meteorological Office, England \\
\hline W. Wiscombe & & HR & NASA Goddard Space Flight Center, USA \\
\hline
\end{tabular}

LBL, HR, and LR denote line-by-line, high-resolution, and low-resolution models, respectively.

on a firm footing first; accordingly, a majority of the cases in the present exercises involved clear-sky conditions. Two solar zenith angles $\left(30^{\circ}\right.$ and $\left.75^{\circ}\right)$ were chosen to correspond to small (nearly 1.25) and large (nearly 4) air masses, respectively; this allows the investigation of the influence of large paths on molecular absorption and that of grazing incidence on scattering. The surface albedos chosen were 0.2 and 0.8 ; the first value may be considered as representative of some land surface, whereas the second one is extreme and was chosen to test the ability of the radiation codes in handling multiple reflections between the surface and the atmosphere. The $\mathrm{CO}_{2}$ concentration was chosen at $300 \mathrm{ppmv}$, instead of the present concentration, for purely historical reasons, because some results were already available for that case.

The approach adopted for the numerical intercomparisons was similar to that used for the longwave cases that have already been reported by Luther et al. [1988]: to start with simple cases, gradually increasing in complexity. The simplest cases correspond to purely absorbing atmospheres; molecular scattering and clouds or aerosols, added successively, increase the complexity of the radiative transfer problem.
A total of $\mathbf{3 0}$ different sets of calculations were submitted for comparison; of these, 26 remained after circulation of the results among the participants. Some results have been withdrawn by the participants after discovering errors (misunderstanding of the instructions or bugs in the program). The final 26 radiation codes come from 22 different participants, some having submitted results from more than one model. The list of participants is given in Table 2. As was the case for the longwave intercomparison, the codes included some too detailed to be employed in climate models as well as $11 \mathrm{GCM}$ radiation algorithms (see Table 2). Two lineby-line (LBL) codes are also included in the comparisons for the purely absorbing cases. LBL calculations for the midlatitude summer atmosphere [McClatchey et al., 1972] have also been performed for a cloud case (case 49 of Table 1 ). In addition, a comparison of very detailed LBL models, with a complete treatment of multiple scattering, has been performed for limited spectral intervals by two of the participants. Among the 26 radiation codes, there are also 13 wideband models suitable for use in climate models and 11 narrow-band models. To get a better understanding of the causes of the divergences between the individual results, a

TABLE 3. Summary of the Statistical Results of the ICRCCM Test Cases Performed for Purely Absorbing Water Vapor Atmosphere

\begin{tabular}{|c|c|c|c|c|c|c|c|c|c|c|c|}
\hline \multirow[b]{2}{*}{ Case } & \multirow[b]{2}{*}{$\begin{array}{l}\text { No. of } \\
\text { Models }\end{array}$} & \multicolumn{5}{|c|}{ Downward Flux at the Surface } & \multicolumn{5}{|c|}{ Total Atmospheric Absorption } \\
\hline & & $\begin{array}{l}\text { LBL1, } \\
W / \mathbf{m}^{2}\end{array}$ & $\begin{array}{l}\text { LBL2, } \\
W / \mathbf{m}^{2}\end{array}$ & $\begin{array}{l}\text { Median, } \\
\mathrm{W} / \mathrm{m}^{2}\end{array}$ & $\begin{array}{c}\text { Range, } \\
\%\end{array}$ & $\underset{\%}{\text { rms difference, }}$ & $\begin{array}{l}\text { LBL1, } \\
\mathrm{W} / \mathrm{m}^{2}\end{array}$ & $\begin{array}{l}\text { LBL2, } \\
\mathbf{W} / \mathbf{m}^{2}\end{array}$ & $\begin{array}{l}\text { Median, } \\
\mathrm{W} / \mathrm{m}^{2}\end{array}$ & $\begin{array}{c}\text { Range, } \\
\%\end{array}$ & $\underset{\%}{\mathrm{rms}}$ \\
\hline 1 & 24 & 1014.2 & 1009.7 & 1019.0 & 4 & 1 & 172.4 & 178.2 & 167.0 & 21 & 5 \\
\hline 2 & 24 & 286.2 & 283.9 & 289.0 & 6 & 2 & 67.1 & 69.6 & 64.2 & 25 & 7 \\
\hline 3 & 24 & 999.3 & 993.1 & 1004.2 & 4 & 1 & 187.8 & 195.4 & 181.9 & 21 & 6 \\
\hline 4 & 24 & 281.0 & 277.9 & 284.0 & 7 & 2 & 72.3 & 75.7 & 69.3 & 31 & 8 \\
\hline 5 & 24 & 1089.5 & 1085.0 & 1084.3 & 6 & 1 & 94.5 & 99.7 & 98.9 & 61 & 11 \\
\hline 6 & 24 & 313.7 & 312.0 & 312.8 & 4 & 1 & 39.3 & 41.1 & 40.1 & 29 & 6 \\
\hline
\end{tabular}

LBL1 and LBL2 refer to two line-by-line calculations. The characteristics of the different test cases are given in Table 1. 
questionnaire was distributed among the participants, and the responses are used in the following analyses.

\section{Purely Absorbing Cases}

A total of 30 different cases correspond to calculations with absorption only. They include three atmospheric profiles ranging from the dry sub-Arctic winter (SAW) atmosphere to the mid-latitude summer (MLS) and tropical (TRO) atmospheres, two different solar zenith angles $\left(30^{\circ}\right.$ and $\left.75^{\circ}\right)$ and two $\mathrm{CO}_{2}$ concentrations ( 300 and $600 \mathrm{ppmv}$ ).

Tables 3, 7, and 8 give a statistical summary of the calculations performed for the purely absorbing cases. The tables show, for both the downward flux at the surface and the total atmospheric absorption, medians of the band model values, the $L B L$ values wherever available, the root-meansquare (rms) difference from the median values, and the total range of the results (difference between the largest and the smallest values) expressed as percent of the median value. The median is defined as that value which separates the set of data into two equal parts (50\% smaller and greater, respectively); if the number of data is even, the median is the arithmetic mean of the two central values, otherwise it is the central value. The rms difference is defined as

$$
\left(\sum_{i=1}^{N}\left(x_{i}-x_{\mathrm{ref}}\right)^{2} /(N-1)\right)^{1 / 2}
$$

where $x_{\text {ref }}$ is a reference (here, the median of the data set). The median value is chosen here because it is not sensitive to the outlying data points.

The total atmospheric absorption is defined as

$$
\mathrm{Abs}=\left(\mathrm{F}_{\mathrm{TOA}}^{\downarrow}-F_{\mathrm{TOA}}^{\uparrow}\right)-F_{S}^{\downarrow}-F_{S}^{\uparrow}
$$

where $F_{\mathrm{TOA}}^{\downarrow}$ and $F_{\mathrm{TOA}}$ are the downward and upward fluxes at the top of the atmosphere (TOA), respectively, and $F_{S}$ and $F_{S} \uparrow$ the downward and upward fluxes at the surface.

Line-by-line results were not available for the higher $\mathrm{CO}_{2}$ amount and the $\mathrm{O}_{3}$ cases.

\subsection{Water Vapor Only}

As a whole, 24 codes including two LBL solutions were available for the case of pure water vapor absorption. Table 3 shows that there are already large differences between the LBL calculations. LBL2 gives downward fluxes at the surface which are systematically smaller by $0.5-1 \%$ than those given by LBL1. In terms of total atmospheric absorption, the differences are 3-5\% with larger absorptions for LBL2.

(Ramaswamy and Freidenreich [this issue] have investigated the cause of these differences. LBL1 absorption computations fall below those of LBL2 due to neglect of three spectral intervals: $0-1000,1000-2600$, and $14,500-18,000$ $\mathrm{cm}^{-1}$. The first two intervals have a small value of solar irradiance associated with them, while the third is weakly absorbing. In the MLS atmosphere, inclusion of these intervals increases the water vapor absorption by $7.3(3.3) \mathrm{W} / \mathrm{m}^{2}$ for solar zenith angles of $30^{\circ}\left(75^{\circ}\right)$; surface fluxes decrease by a corresponding amount. The underestimate in the atmospheric absorption due to neglect of these is $4.3 \%$ and $4.8 \%$ for zenith angles of $30^{\circ}$ and $75^{\circ}$, respectively. Both LBL1 and
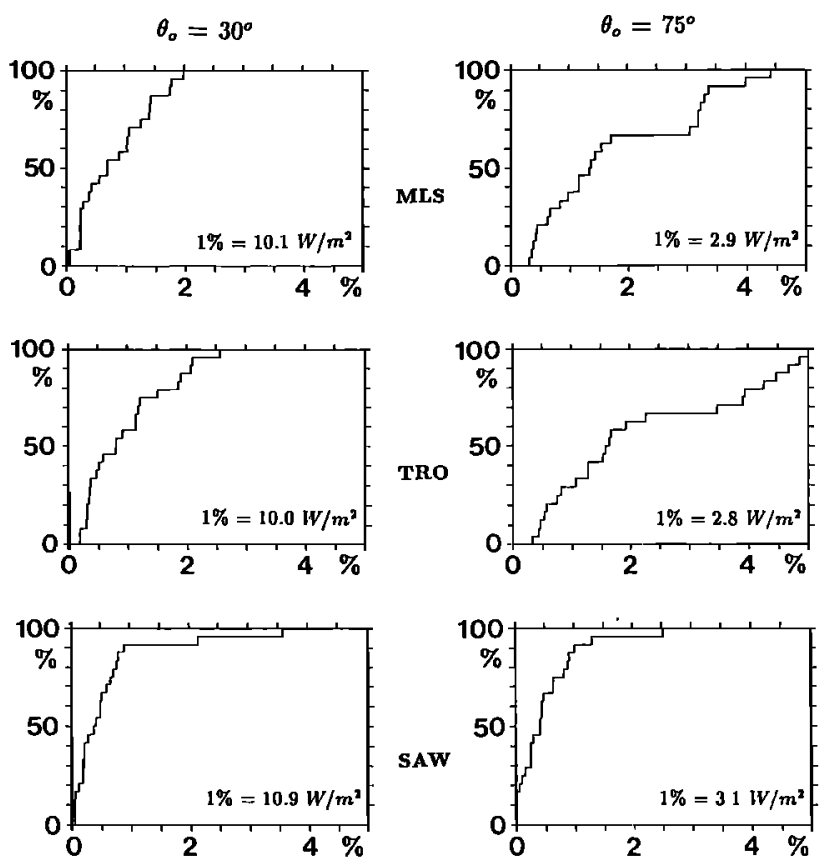

Fig. 1. Cumulative frequency distribution of the downward flux at the surface for the water vapor only cases $(100 \%=23$ values). The ordinate represents the percentage difference in the fluxes (the column on the left is for a zenith angle of $30^{\circ}$, while the column on the right is for $75^{\circ}$ ); the coordinate represents the fraction of models which yield a flux difference less than a particular ordinate value. The three sets of panels represent different atmospheric profiles.

LBL2 make use of the Air Force Geophysics Laboratory (AFGL) spectral data bank.

The effect on the individual layer absorption due to neglect of the spectral intervals is minimal. Thus the heating rates from the two LBL model calculations are within $1 \%$ of each other. This, coupled with the fact that the flux differences over the entire spectrum (barring the intervals mentioned above) are less than $2 \mathrm{~W} / \mathrm{m}^{2}$, must be interpreted as an excellent agreement between the two LBL codes.)

The band model results are analyzed by comparing them with the mean of the line-by-line results. For the downward fluxes at the surface, the differences between the median and the $L B L$ results are very similar to those between the two LBLs. The rms differences are from $1 \%$ to $3 \%$, with the range being $3-8 \%$ of the LBL results. For the atmospheric absorption, the absolute differences between the median and the LBL values are significantly larger, and the relative differences are obviously much larger, from $2 \%$ to nearly $6 \%$ (not shown). The rms differences are between $6 \%$ and $11 \%$, while the total ranges are considerable, from $20 \%$ to $30 \%$ and up to $62 \%$ for the driest case (sub-Arctic winter atmosphere).

In Figures 1 and 2, the results of the variations among the models are presented according to a cumulative histogram for the downward surface flux and the total atmospheric absorption, respectively. The ordinate represents the percentage difference in the fluxes (the column on the left is for a zenith angle of $30^{\circ}$, while the column on the right is for $75^{\circ}$ ); the coordinate represents the fraction of models which yield a flux difference less than a particular ordinate value. The three sets of panels represent three different atmospheric profiles. On these figures, if a line exhibits a large discontinuity, it indicates that a single code exerts a substantial 

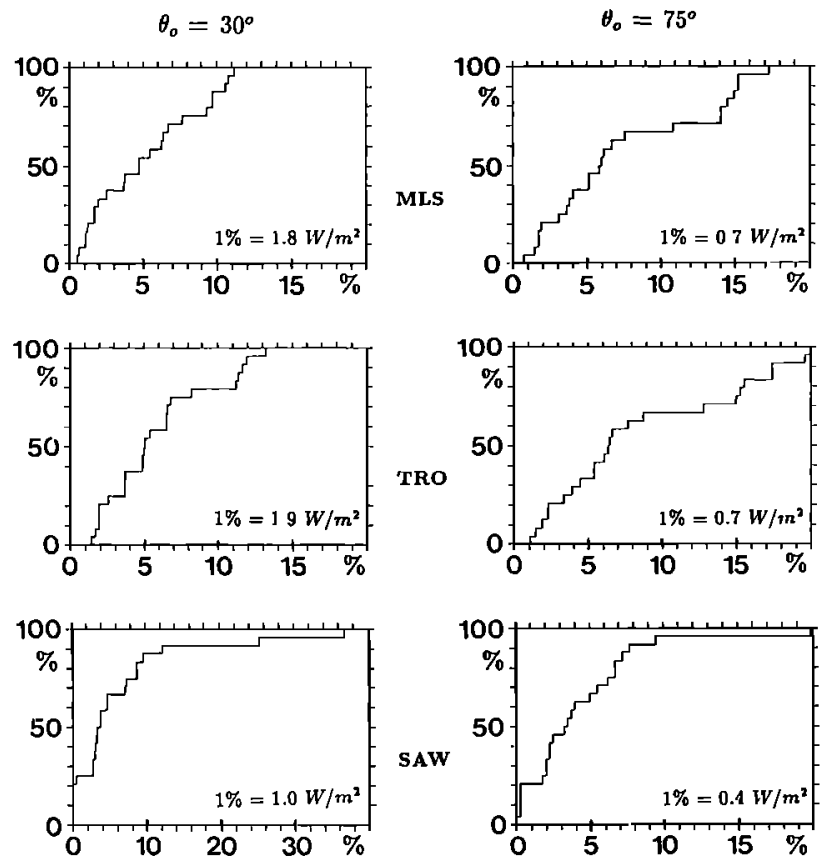

Fig. 2. As in Figure 1 but for the total atmospheric absorption.

impact on the total discrepancy. It can be seen that the extremely large range observed for the sub-Arctic winter atmospheric profile is due to a single code using parameterizations which apparently strongly underestimates the water vapor absorption for the small water paths. According to Figure 1, about half of the calculated surface fluxes agree to within $\pm 0.5 \%$ of the LBL results for $\theta_{0}=30^{\circ}$ and to $\pm 1 \%$ for $\theta_{0}=75^{\circ}$. The agreement is much poorer for the atmospheric absorption (Figure 2): $50 \%$ of the models are within $5 \%$ of the $L B L$ results.

\subsection{Analysis of Models}

A detailed analysis of these comparisons provides some reasons for the observed discrepancies. From Table 3, it is seen that the medians of the band models (i.e., the models other than LBLs) indicate an absorption that is smaller than the corresponding LBL values for the wet tropical atmosphere, but that is comparable for the dry sub-Arctic winter atmosphere. This is true for $\theta_{0}=30^{\circ}$ as well as for $\theta_{0}=75^{\circ}$, although the underestimate is greater when the water vapor path is the largest (i.e., for the tropical atmosphere with $\theta_{0}=$ $30^{\circ}$ and $75^{\circ}$ ).

To analyze the behavior of the band models, the results are sorted out in Table 4 according to the number of spectral intervals employed. Besides the two LBL models, 21 other models were categorized as low-resolution (LR) or highresolution (HR), with the latter designation attributed to those with 10 or more spectral intervals. (One model was not affiliated with any group, since information on its spectral resolution was unavailable.) The median, range, and rms differences that emerge in Table 4 for the two categories are similar to those evident in Table 3 . This suggests that the tendencies in the values given by the various models are independent of the spectral resolution employed. The smaller range of the LR codes is, in part, attributable to the similarities in their respective parameterizations.

The absorption of solar radiation in the atmosphere involves the calculation of the spectral transmission as well as its convolution with the incoming solar flux. The problems involved with the computation of the spectral transmission are quite similar to the longwave case studies, viz., they depend on the quality of the spectral data, the line shape, its dependence on pressure and temperature, the particular band model employed, and its spectral resolution. The convolution with the solar spectrum adds a further significance to the spectral resolution employed owing to the spectral variations of the incoming flux. The ICRCCM instructions required the use of Labs and Neckel's [1970] values for the solar spectrum with the recent update for the 0.33- to 1.25- $\mu \mathrm{m}$ region [Neckel and Labs, 1984]. Some authors, however, made use of other data [e.g., Thekaekara and Drummond, 1971]; this choice had no detectable impact on the comparisons. Separate tests with a high spectral resolution code yielded differences substantially less than $1 \%$ between using the two sets of irradiances (Table 5).

To investigate further the results of the band models, we considered a high-resolution radiation code and systematically modified some of its initial assumptions. The model has a spectral resolution of $20 \mathrm{~cm}^{-1}$, it makes use of the Malkmus [1967] random band model including, initially, Fels's [1979] approximation for the Voigt spectral line shape and the Curtis-Godson approximation (CGA) [Curtis, 1952; Godson, 1953] to account for the pressure and temperature effects; the spectral parameters are those of the AFGL 1982 spectral data bank [Rothman et al., 1987]. Table 5 shows a systematic decrease of the absorption by roughly $0.7-1 \%$

TABLE 4. Total Atmospheric Absorption for the Six Cases Concerning the Absorption by Water Vapor Only

\begin{tabular}{|c|c|c|c|c|c|c|c|c|c|c|c|}
\hline \multirow[b]{2}{*}{ Case } & \multirow[b]{2}{*}{$\theta_{0}, \operatorname{deg}$} & \multicolumn{2}{|c|}{$\mathrm{LBL}, \mathrm{W} / \mathrm{m}^{2}$} & \multicolumn{2}{|c|}{ Median, $\mathrm{W} / \mathrm{m}^{2}$} & \multicolumn{2}{|c|}{ Range, \% } & \multicolumn{2}{|c|}{$\begin{array}{c}\text { rms } \\
\text { Differences, } \\
\%\end{array}$} & \multicolumn{2}{|c|}{$\begin{array}{c}\text { No. of } \\
\text { Models }\end{array}$} \\
\hline & & 1 & 2 & HR & LR & HR & LR & HR & LR & HR & LR \\
\hline MLS & 30 & 172.4 & 178.2 & 171.0 & 165.7 & 12 & 11 & 6 & 7 & 10 & 11 \\
\hline MLS & 75 & 67.1 & 69.6 & 62.4 & 64.3 & 21 & 14 & 11 & 10 & 10 & 11 \\
\hline TRO & 30 & 187.8 & 195.4 & 181.9 & 181.2 & 16 & 12 & 7 & 8 & 10 & 11 \\
\hline TRO & 75 & 72.3 & 75.7 & 66.9 & 69.2 & 29 & 14 & 14 & 10 & 10 & 11 \\
\hline SAW & 30 & 94.5 & 99.7 & 101.7 & 97.1 & 49 & 14 & 14 & 4 & 10 & 11 \\
\hline SAW & 75 & 39.3 & 41.1 & 41.1 & 39.5 & 17 & 10 & 6 & 4 & 10 & 11 \\
\hline
\end{tabular}

The band models are grouped in two classes according to their spectral resolution (HR and LR for high and low resolution, respectively: see Table 2). 
TABLE 5. Influence of Spectral Resolution, Line Shape, Pressure, and Temperature Dependences on the Atmospheric Water Vapor Absorption

\begin{tabular}{|c|c|c|c|c|c|c|c|c|}
\hline \multirow{2}{*}{$\begin{array}{c}\text { Line } \\
\text { Shape }\end{array}$} & \multirow{2}{*}{$\begin{array}{c}\text { Spectral } \\
\text { Resolution, } \\
\mathrm{cm}^{-1}\end{array}$} & \multirow{2}{*}{$\begin{array}{l}\text { Pressure and } \\
\text { Temperature } \\
\text { Dependence }\end{array}$} & \multicolumn{2}{|c|}{ MLS } & \multicolumn{2}{|c|}{ TRO } & \multicolumn{2}{|c|}{ SAW } \\
\hline & & & $30^{\circ}$ & $75^{\circ}$ & $30^{\circ}$ & $75^{\circ}$ & $30^{\circ}$ & $75^{\circ}$ \\
\hline Voigt & 20 & CGA & 168.9 & 65.9 & 184.6 & 71.1 & 97.2 & 40.3 \\
\hline Lorentz & 20 & CGA & 167.5 & 65.1 & 182.7 & 70.3 & 96.5 & 39.9 \\
\hline Lorentz & 20 & SA & 163.0 & 63.7 & 177.8 & 68.9 & 95.1 & 39.5 \\
\hline Voigt & 100 & CGA & 172.7 & 67.1 & 188.4 & 72.3 & 100.0 & 41.3 \\
\hline Lorentz & 100 & CGA & 171.2 & 66.6 & 187.0 & 71.8 & 98.9 & 40.9 \\
\hline Lorentz & 100 & SA & 169.6 & 66.2 & 185.5 & 71.6 & 97.2 & 40.4 \\
\hline Voigt & 20 & CGA & 168.6 & 65.6 & 184.1 & 70.8 & 97.5 & 40.3 \\
\hline
\end{tabular}

Unit of measure is $\mathrm{W} / \mathrm{m}^{2}$. The CGA and SA abbreviations are for the Curtis-Godson and scaling approximations, respectively. The last row is the same as the first except that Thekaekara and Drummonds' [1971] solar irradiance data are used instead of Labs and Neckel's [1970].

when the Lorentz line shape is used instead of the Voigt profile. This apparently small difference in the total atmospheric absorption is linked to the fact that most of the water vapor is concentrated in the lower troposphere, where collisional broadening occurs and which is well represented by the Lorentz profile. However, these differences are systematic, and $1 \%$ is a significant part of the rms differences observed in the comparisons of the total atmospheric absorption. The systematic character of the difference is caused by the underestimate of the line widths at low pressures by the Lorentz profile. Thus in the stratosphere, where the pressures are low, larger relative differences may occur in the absorbed flux.

When a scaling approximation is used, in which the absorber amount, pressure, and temperature dependences are reduced to a single dependent parameter (one parameter approximation, SA), the decrease in absorption ranges from $0 \%$ to $4 \%$ at $20 \mathrm{~cm}^{-1}$ resolution; it increases up to $3 \%$ when the resolution is degraded to $100 \mathrm{~cm}^{-1}$. Note that almost all wideband codes make use of the scaling approximation in one form or another. In the present case, the exponent for the pressure scaling [Lacis and Hansen, 1974] was 0.9. As a caution, it is pointed out that it is probably unlikely that a single exponent will yield excellent results under all circum- stances, ranging from, say, the warm, humid tropical to the cold, dry sub-Arctic conditions.

The resolution at which the solar attenuation is calculated has an important impact both through the accuracy of the transmission functions themselves (similar to the longwave results of Kiehl and Ramanathan [1983]) and through the convolution with the solar flux. Table 5 shows that a resolution of $100 \mathrm{~cm}^{-1}$ instead of $20 \mathrm{~cm}^{-1}$ results in enhanced absorption ( $\simeq 2$ to nearly $3 \%$ for the SAW case). In this particular instance, there is a compensation of errors. Note that the Lorentz SA $100 \mathrm{~cm}^{-1}$ result is similar to the Voigt GGA $20 \mathrm{~cm}^{-1}$ result. This illustrates the fact that, in some instances, compensation of errors, though yielding the correct result, can offer an incorrect perspective. Table 5 also shows that the spectral resolution at which the convolution is performed has a strong impact and can lead to significant errors. Note that, in the near infrared, the solar spectrum may not be known with sufficient accuracy to conclude definitively that convolutions of solar insolation with transmissions are more realistic at $20 \mathrm{~cm}^{-1}$ resolution than at $100 \mathrm{~cm}^{-1}$.

In Table 6 the atmospheric absorptions are sorted out according to the method used to calculate the band transmissions. As far as the spectral data are concerned, all

TABLE 6. Same as Table 4, but With the Models Grouped According to the Initial Spectral Data

\begin{tabular}{|c|c|c|c|c|c|c|}
\hline & \multicolumn{2}{|c|}{ MLS } & \multicolumn{2}{|c|}{ TRO } & \multicolumn{2}{|c|}{ SAW } \\
\hline & $30^{\circ}$ & $75^{\circ}$ & $30^{\circ}$ & $75^{\circ}$ & $30^{\circ}$ & $75^{\circ}$ \\
\hline LBL $1, \mathrm{~W} / \mathrm{m}^{2}$ & 172.4 & 67.1 & 187.8 & 72.3 & 94.5 & 39.3 \\
\hline $\mathrm{LBL} 2, \mathrm{~W} / \mathrm{m}^{2}$ & 178.2 & 69.6 & 195.4 & 75.7 & 99.7 & 41.1 \\
\hline \multicolumn{7}{|l|}{ No. of Models } \\
\hline AFGL & 9 & 9 & 9 & 9 & 9 & 9 \\
\hline LOWTRAN & 5 & 5 & 5 & 5 & 5 & 5 \\
\hline Others & 7 & 7 & 7 & 7 & 7 & 7 \\
\hline \multicolumn{7}{|l|}{ Median, $\mathrm{W} / \mathrm{m}^{2}$} \\
\hline AFGL & 168.9 & 64.9 & 182.2 & 70.0 & 97.2 & 40.3 \\
\hline LOWTRAN & 158.3 & 58.8 & 169.8 & 62.9 & 100.8 & 39.4 \\
\hline Others & 165.7 & 64.3 & 181.2 & 69.3 & 97.2 & 39.4 \\
\hline \multicolumn{7}{|l|}{ Range, \% } \\
\hline AFGL & 13 & 19 & 16 & 22 & 17 & 15 \\
\hline LOWTRAN & 11 & 21 & 16 & 26 & 49 & 16 \\
\hline Others & 10 & 9 & 9 & 9 & 13 & 11 \\
\hline \multicolumn{7}{|c|}{ rms difference, $\%$} \\
\hline AFGL & 6 & 11 & 7 & 13 & 6 & 5 \\
\hline LOWTRAN & 9 & 14 & 11 & 16 & 20 & 6 \\
\hline Others & 6 & 6 & 6 & 6 & 5 & 4 \\
\hline
\end{tabular}




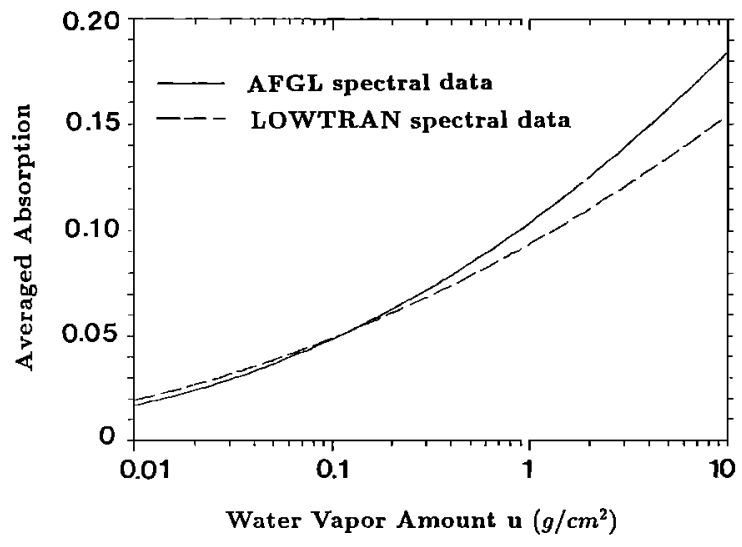

Fig. 3. Spectrally averaged water vapor absorption $(0.25-4.0$ $\mu \mathrm{m})$. Molecular transmissions calculated from either a Malkmus random-band model (AFGL) or by the LOWTRAN code are convoluted with the extraterrestrial solar flux [Labs and Neckel, 1970; Neckel and Labs, 1984].

participants (other than the LBLs) made use of either the Lacis and Hansen [1974] (equivalently, the Yamamoto [1962] parameterization) or the various versions of the narrow-band LOWTRAN code [Selby et al., 1978], or used a random-band model in conjunction with the AFGL spectral data base. The results are collectively presented in Table 6 . The designation "others" denotes the results obtained from parameterizations; also listed are the corresponding results from the LBL computations. Table 6 clearly shows that there are systematic differences between the results based upon the LOWTRAN code and those based on random-band models for all three atmospheres; an analysis (not presented here) shows that this tendency is independent of the spectral resolution. Figure 3 confirms this result: it shows the variation with the water vapor path of the spectrally averaged water vapor absorption taking account of the solar spectral variations. A separate analysis showed that the LOWTRAN code tends to underestimate the absorption in the wings of the bands for large water vapor paths. According to Table 6, this leads to quite significant differences (up to $9 \%$, or $15 \mathrm{~W}$ $\mathrm{m}^{-2}$ ). Note that the median values of the codes using AFGL data base are closer to the LBL2 than are those using LOWTRAN. An exception to this is the SAW $30^{\circ}$ case, where LOWTRAN-based models appear to be in better agreement with the LBL2 results. In terms of downward surface fluxes, the biases introduced by the different methods amount to $10 \%$ for the tropical atmosphere. This value is climatically significant if we consider the upper limit in uncertainty of $<10 \mathrm{~W} \mathrm{~m}^{-2}$, set forth for the surface fluxes in the Tropical Ocean and Global Atmosphere Experiment (TOGA).

As far as the present sets of results are concerned, there is no question that the LBL codes, since they account for all the individual molecular extinction spectra and use the state-of-art knowledge in radiative transfer, yield the most rigorous solutions (benchmarks). Thus they offer the most accurate means of calibrating the vertical distribution of fluxes and heating rates in climate models. However, it must be pointed out that the present theory could contain fundamental uncertainties in the spectral details and solar irradiance values, so that the ultimate and complete validation test would be one involving the comparison of the theoretically based computations with field (and laboratory) measurements. For this purpose, it is recommended that comprehensive field experiments be undertaken in which the radiative quantities and all relevant meteorological parameters are determined with high precision.

\subsection{Water Vapor and Uniformly Mixed Gases $\left(\mathrm{CO}_{2}\right.$ and $\left.\mathrm{O}_{2}\right)$}

The results of the calculations including $\mathrm{CO}_{2}$ and $\mathrm{O}_{2}$ absorption cases 7-18 are summarized in Table 7 . The additional absorption is small and not significant; according to the LBL calculations, it represents less than $5 \%$ of the total atmospheric absorption (10\% for the sub-Arctic winter atmosphere) and less than $1 \%$ of $F_{S}$. Note, however, that in comparison to the LBL results, the band models yield larger values for $F_{S}^{\downarrow}$; this compensates to some extent the systematic differences of the opposite sign observed for pure water vapor absorption. Doubling the atmospheric $\mathrm{CO}_{2}$ concentration increases the total atmospheric absorption by $1-2 \%$, the largest effect occurring for the sub-Arctic winter case, when the water vapor absorption is minimum. The maximum decrease of $F_{S}^{\downarrow}$ for $1 \times \mathrm{CO}_{2}$ is about $0.7 \%$. Because of the small additional absorption, the spread in the results is not significantly modified over and above that for water vapor absorption.

TABLE 7. Same as Table 3 but for Cases Including Absorption by Carbon Dioxide and Oxygen

\begin{tabular}{|c|c|c|c|c|c|c|c|c|c|}
\hline \multirow[b]{2}{*}{ Case } & \multirow[b]{2}{*}{$\begin{array}{l}\text { No. of } \\
\text { Models }\end{array}$} & \multicolumn{4}{|c|}{ Downward Flux at the Surface } & \multicolumn{4}{|c|}{ Total Atmospheric Absorption } \\
\hline & & $\begin{array}{l}\text { LBL1, } \\
W / \mathrm{m}^{2}\end{array}$ & $\begin{array}{l}\text { Median, } \\
\mathrm{W} / \mathrm{m}^{2}\end{array}$ & $\begin{array}{c}\text { Range, } \\
\%\end{array}$ & $\begin{array}{c}\text { rms Difference, } \\
\%\end{array}$ & $\begin{array}{l}\text { LBL 1, } \\
W / \mathbf{m}^{2}\end{array}$ & $\begin{array}{l}\text { Median, } \\
\mathrm{W} / \mathrm{m}^{2}\end{array}$ & $\begin{array}{c}\text { Range, } \\
\%\end{array}$ & $\begin{array}{c}\text { rms Difference, } \\
\%\end{array}$ \\
\hline 7 & 17 & 1006.5 & 1008.6 & 4 & 1 & 180.7 & 178.4 & 19 & 5 \\
\hline 8 & 16 & & 1005.5 & 4 & 1 & & 181.5 & 19 & 5 \\
\hline 9 & 17 & 282.7 & 285.7 & 6 & 2 & 70.7 & 67.6 & 24 & 7 \\
\hline 10 & 16 & & 285.0 & 6 & 2 & & 68.2 & 25 & 7 \\
\hline 11 & 17 & 991.8 & 993.7 & 4 & 1 & 195.8 & 193.1 & 19 & 6 \\
\hline 12 & 16 & & 990.8 & 4 & 1 & & 194.9 & 20 & 6 \\
\hline 13 & 17 & 277.6 & 280.3 & 7 & 2 & 75.8 & 73.0 & 28 & 8 \\
\hline 14 & 16 & & 279.7 & 8 & 2 & & 73.7 & 28 & 9 \\
\hline 15 & 17 & 1080.9 & 1073.7 & 5 & 1 & 103.9 & 110.7 & 75 & 15 \\
\hline 16 & 16 & & 1070.8 & 5 & 1 & & 113.9 & 45 & 10 \\
\hline 17 & 17 & 309.7 & 308.2 & 3 & 1 & 43.4 & 45.3 & 22 & 6 \\
\hline 18 & 16 & & 307.1 & 3 & 1 & & 46.5 & 22 & 6 \\
\hline
\end{tabular}


TABLE 8. Same as Table 7 but for Cases Including Absorption by Ozone

\begin{tabular}{|c|c|c|c|c|c|c|c|}
\hline \multirow[b]{2}{*}{ Case } & \multirow[b]{2}{*}{$\begin{array}{l}\text { No. of } \\
\text { Models }\end{array}$} & \multicolumn{3}{|c|}{ Downward Flux at the Surface } & \multicolumn{3}{|c|}{ Total Atmospheric Absorption } \\
\hline & & $\begin{array}{l}\text { Median, } \\
\mathrm{W} / \mathrm{m}^{2}\end{array}$ & $\begin{array}{c}\text { Range, } \\
\%\end{array}$ & $\begin{array}{c}\text { rms Difference, } \\
\%\end{array}$ & $\begin{array}{l}\text { Median, } \\
\mathrm{W} / \mathrm{m}^{2}\end{array}$ & $\underset{\%}{\text { Range, }}$ & $\begin{array}{c}\text { rms Difference, } \\
\%\end{array}$ \\
\hline 19 & 21 & 982.1 & 4 & 1 & 207.2 & 18 & 5 \\
\hline 20 & 16 & 977.6 & 4 & 1 & 212.7 & 15 & 5 \\
\hline 21 & 21 & 270.0 & 8 & 2 & 83.6 & 17 & 6 \\
\hline 22 & 16 & 268.3 & 8 & 2 & 85.8 & 17 & 6 \\
\hline 23 & 21 & 970.5 & 5 & 1 & 218.6 & 16 & 5 \\
\hline 24 & 16 & 965.6 & 5 & 1 & 223.5 & 15 & 5 \\
\hline 25 & 21 & 269.5 & 9 & 2 & 84.1 & 21 & 7 \\
\hline 26 & 16 & 265.8 & 9 & 3 & 88.2 & 21 & 7 \\
\hline 27 & 21 & 1039.8 & 6 & 1 & 149.2 & 40 & 9 \\
\hline 28 & 16 & 1035.9 & 5 & 1 & 153.2 & 37 & 8 \\
\hline 29 & 21 & 288.6 & 6 & 2 & 65.6 & 27 & 7 \\
\hline 30 & 16 & 286.2 & 7 & 1 & 68.2 & 22 & 5 \\
\hline
\end{tabular}

\subsection{Including Ozone Absorption}

Table 8 shows the summary of the comparison for the cases 19-30 including ozone absorption. No LBL results were available for these cases. Most participants made use of either Lacis and Hansen's [1974] parameterization, which is based on data by Vigroux [1953] and Inn and Tanaka [1953], or Ackerman's [1971] observations, or various versions of the LOWTRAN code. According to Table 8, there is no significant increase in the dispersion when $\mathrm{O}_{3}$ absorption, too, is considered. The standard deviation of the additional absorption (not shown here) is 10-12\%; however, some codes differ considerably from the others, and the spread in the additional absorption due to $\mathrm{O}_{3}$ amounts to a maximum of $67 \%$ for the sub-Arctic winter case.

In summary, for the purely absorbing gas only cases (Tables 3, 7, and 8) the rms differences are 1-3\% for $F_{S}^{\downarrow}$, $19 \%$ for Abs, and the spread may amount to about $40 \%$ in Abs. The largest relative discrepancies occur when absorption values are small, i.e., for the relatively dry sub-Arctic winter atmosphere.

\section{Molecular Scattering}

A set of 12 cases ( $31-42)$ correspond to calculations for all constituents $\left(\mathrm{H}_{2} \mathrm{O}, \mathrm{CO}_{2}, \mathrm{O}_{2}, \mathrm{O}_{3}\right)$ and molecular scattering. They included the same atmospheric profiles and sun angles and two surface albedos, a low $\left(\rho_{s}=0.2\right)$ and a high value ( $\rho_{s}$ $=0.8$ ), respectively. A total of 21 codes were available for these cases but no LBL at the time of the comparison. Table 9 summarizes the results corresponding to this part of the comparison. The rms differences amount to $\simeq 4 \%$ for $F_{S}^{\downarrow}$ at low solar elevations, which is nearly twice those for the purely absorbing cases. The range in values increases to nearly $20 \%$. The rms difference and the range of Abs increase only slightly over the purely absorbing cases for $\rho_{s}=0.2$. For the large albedo cases $\left(\rho_{s}=0.8\right)$, the range in Abs can differ by as much as $50 \%$ relative to that for the lower albedo surface. This highlights the difficulty of adequately modeling multiple scattering over highly reflecting surfaces.

Figure 4 shows, for the mid-latitude summer atmosphere, the changes induced in $F_{S}^{\downarrow}$ by the addition of molecular scattering. In this figure the results are sorted out according to their spectral resolution and again presented as cumulative histograms. As in Figures 1 and 2, the ordinate represents the percentage deviation from the median of the high-resolution codes, while the coordinate denotes the fraction of models which have values less than a specific ordinate value. Four different categories of models are considered: HR models only, LR models only, LR models consisting of Rayleigh parameterization, and a subset of the HR models. The impact of the spectral resolution appears

TABLE 9. Statistics of the Results for the Cases Including Molecular Scattering

\begin{tabular}{|c|c|c|c|c|c|c|c|c|c|c|}
\hline \multirow[b]{2}{*}{ Case } & \multirow[b]{2}{*}{$\begin{array}{l}\text { Atmospheric } \\
\text { Profile }\end{array}$} & \multirow[b]{2}{*}{$\begin{array}{c}\text { Zenith } \\
\text { Angle, deg }\end{array}$} & \multirow[b]{2}{*}{$\begin{array}{c}\text { Surface } \\
\text { Reflectance }\end{array}$} & \multirow[b]{2}{*}{$\begin{array}{l}\text { No. of } \\
\text { Models }\end{array}$} & \multicolumn{3}{|c|}{ Downward Flux at the Surface } & \multicolumn{3}{|c|}{ Total Atmospheric Absorption } \\
\hline & & & & & $\underset{W / m^{2}}{\text { Median, }}$ & $\begin{array}{c}\text { Range, } \\
\%\end{array}$ & $\begin{array}{c}\text { rms Difference, } \\
\%\end{array}$ & $\begin{array}{l}\text { Median, } \\
W / \mathbf{m}^{2}\end{array}$ & $\begin{array}{c}\text { Range, } \\
\%\end{array}$ & $\begin{array}{c}\text { rms Difference, } \\
\%\end{array}$ \\
\hline 31 & MLS & 30 & 0.2 & 21 & 943.7 & 5 & 2 & 206.2 & 21 & 6 \\
\hline 32 & MLS & 30 & 0.8 & 21 & 985.0 & 5 & 2 & 245.3 & 29 & 8 \\
\hline 33 & MLS & 75 & 0.2 & 21 & 235.8 & 10 & 2 & 83.8 & 16 & 5 \\
\hline 34 & MLS & 75 & 0.8 & 21 & 246.2 & 17 & 4 & 89.2 & 22 & 7 \\
\hline 35 & TRO & 30 & 0.2 & 21 & 932.6 & 6 & 2 & 215.1 & 19 & 6 \\
\hline 36 & TRO & 30 & 0.8 & 21 & 975.0 & 6 & 2 & 250.6 & 33 & 8 \\
\hline 37 & TRO & 75 & 0.2 & 21 & 234.9 & 11 & 3 & 84.0 & 20 & 6 \\
\hline 38 & TRO & 75 & 0.8 & 21 & 246.5 & 18 & 4 & 91.6 & 25 & 7 \\
\hline 39 & SAW & 30 & 0.2 & 21 & 999.6 & 7 & 1 & 150.6 & 40 & 9 \\
\hline 40 & SAW & 30 & 0.8 & 21 & 1043.7 & 7 & 2 & 181.9 & 38 & 9 \\
\hline 41 & SAW & 75 & 0.2 & 20 & 255.3 & 13 & 3 & 66.2 & 42 & 10 \\
\hline 42 & SAW & 75 & 0.8 & 21 & 265.1 & 13 & 3 & 72.7 & 32 & 8 \\
\hline
\end{tabular}

These cases are distinguished according to the atmospheric profile, solar zenith angle, and surface reflectance (see Table 1). 

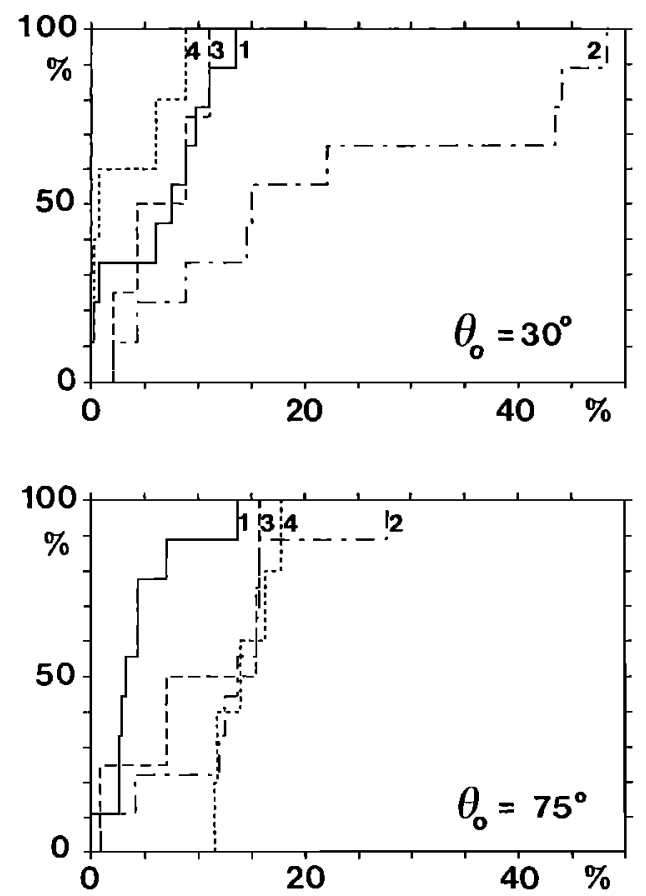

Fig. 4. Same as Figure 1, except for the changes induced in the downward flux at the surface due to molecular scattering. The two diagrams correspond to the cases 31 and 33 (mid-latitude summer $\theta_{0}$ $=30^{\circ}$ and $75^{\circ}$ ) compared to 19 and 21 , respectively (see Table 1 ). Curve 1 (solid line), high-resolution models (nine results); curve 2 (dash-dot line), low-resolution models (nine results); curve 3 (dashed line), LR and Rayleigh scattering optical depth $\left(\delta_{R}\right)$ parameterized (four results); and curve 4 (dotted line), HR subset (five results).

clearly, as the results of the low-resolution codes tend to systematically deviate from those of the high-resolution ones. This is independent of whether the reflectances and transmittances of the scattering atmosphere are explicitly calculated or parameterized. The cause of the observed larger discrepancies for the low-resolution codes lies in the spectral averaging of the optical parameters, which in the present case, is the Rayleigh optical thickness $\delta_{R}$. Indeed, the strong spectral variation of the Rayleigh scattering $\left(\delta_{R} \propto\right.$ $\lambda^{-4}$ with $\lambda$ being the wavelength) requires that this quantity be chosen with care. This problem is minimized with high or even moderate resolution, say four or five judiciously chosen spectral intervals; however, for LR radiation codes it may be quite serious, as shown in Figure 4. The problem arises due to the dependence of the reflectivity on the sun angle; LR models tend to overestimate the reflection at low solar elevations. A suitable parameterization of $\delta_{R}$ as a function of the sun angle may significantly reduce the amplitude of the corresponding errors (exemplified by curve 3 in Figure 4).

\section{Atmospheres With Clouds}

\subsection{Band Model Intercomparisons}

Six cases (43-49) were selected for testing the shortwave radiation codes in cloudy conditions. The atmospheric profile was the mid-latitude summer one, the sun angle $\theta_{0}=30^{\circ}$, and the surface albedo $\rho_{s}=\mathbf{0 . 2}$. Two drop size distributions were considered, containing small (CS) and large (CL) drops; two integrated liquid water paths, a small and a large one (10 and $200 \mathrm{~g}^{-2}$, respectively) were also considered. These values correspond roughly to the smaller and larger values reported in the literature for boundary layer clouds. The smaller one may, however, be considered as extreme and was observed in Arctic stratus clouds only [Herman and Curry, 1984]. It was chosen as a test case to evaluate the ability of radiation codes to simulate the impact of thin clouds, e.g., cirrus clouds. The CS size distribution is that of Sc I (effective radius $r_{e}=5.25 \mu \mathrm{m}$ ) in Stephens [1979], and the CL size distribution is his $\mathrm{Cb}$ distribution $\left(r_{e}=31 \mu \mathrm{m}\right)$. To restrict the study to the purely computational aspects, the optical thicknesses were specified in the instructions $(\delta=$ 0.48 and 9.70 for the CL cloud and $\delta=2.81$ for the CS cloud). Two different cloud top altitudes were considered: 2 and $13 \mathrm{~km}$. The summary of the results of the cloudy cases is presented in Table 10. The rms differences increase significantly compared to the clear sky cases and range from $2 \%$ to $10 \%$ (relative to the median) for $F_{S}^{\downarrow}$ and from $6 \%$ to $17 \%$ for Abs; the ranges in the atmospheric absorption exceed $50 \%$ for the high, thick cloud case.

Table 11 summarizes the changes in the atmospheric Abs induced by the addition of clouds. In this table the results of the LR codes are distinguished from those of the other model types. Note that, in most cases, the range and the rms differences of the LR codes are such that even the sign of the cloud effect is uncertain. For the case of a thick, low cloud, the additional absorption induced by the cloud ranges up to $75 \mathrm{~W} \mathrm{~m}^{-2}$. This additional absorption absorption is not only due to the absorption in the cloud layer, but also includes the absorption of the reflected light and accounts for the reduced absorption of the transmitted radiation below the cloud.

At first sight, Table 11 shows that that the HR and LR codes often present similar ranges and rms differences. However, a closer examination of the individual results reveals a situation which differs considerably for the two groups. Indeed, the large spread of the HR models is due to some easily identifiable codes, whose results differ system-

TABLE 10. Same as Table 9 but for Cloudy Conditions

\begin{tabular}{|c|c|c|c|c|c|c|c|c|c|c|}
\hline \multirow[b]{2}{*}{ Case } & \multirow[b]{2}{*}{$\begin{array}{l}\text { Cloud } \\
\text { Type }\end{array}$} & \multirow[b]{2}{*}{$\begin{array}{c}\text { Top } \\
\text { Height, km }\end{array}$} & \multirow[b]{2}{*}{ LWP } & \multirow[b]{2}{*}{$\begin{array}{l}\text { No. of } \\
\text { Models }\end{array}$} & \multicolumn{3}{|c|}{ Downward Flux at the Surface } & \multicolumn{3}{|c|}{ Total Atmospheric Absorption } \\
\hline & & & & & $\begin{array}{l}\text { Median, } \\
\mathrm{W} / \mathrm{m}^{2}\end{array}$ & $\begin{array}{c}\text { Range, } \\
\%\end{array}$ & $\begin{array}{c}\text { rms Difference, } \\
\%\end{array}$ & $\begin{array}{l}\text { Median, } \\
\mathrm{W} / \mathrm{m}^{2}\end{array}$ & $\begin{array}{c}\text { Range, } \\
\%\end{array}$ & $\begin{array}{c}\text { rms Difference, } \\
\%\end{array}$ \\
\hline 43 & $\mathrm{CS}$ & 13 & 10 & 17 & 778.8 & 15 & 4 & 203.4 & 37 & 10 \\
\hline 45 & $\mathrm{CS}$ & 2 & 10 & 16 & 782.3 & 15 & 4 & 226.7 & 24 & 7 \\
\hline 46 & $\mathrm{CL}$ & 13 & 10 & 14 & 919.5 & 8 & 2 & 207.6 & 18 & 6 \\
\hline 47 & CL & 13 & 200 & 15 & 536.0 & 38 & 10 & 218.5 & 54 & 17 \\
\hline 48 & $\mathrm{CL}$ & 2 & 10 & 15 & 921.2 & 8 & 2 & 210.8 & 19 & 6 \\
\hline 49 & $\mathrm{CL}$ & 2 & 200 & 15 & 537.1 & 43 & 9 & 255.5 & 35 & 9 \\
\hline
\end{tabular}


TABLE 11. Additional Atmospheric Absorption Induced by the Presence of Cloud Over and Above that Due to All Gases

\begin{tabular}{lcccccc}
\hline & \multicolumn{6}{c}{ Cloud Type } \\
\cline { 2 - 7 } & CS & CS & CL & CL & CL & CL \\
\hline Cloud top altitude, $\mathrm{km}$ & 13 & 2 & 13 & 13 & 2 & 2 \\
Optical thickness & 2.81 & 2.81 & 0.48 & 9.70 & 0.48 & 9.70 \\
No. of Models & & & & & & \\
All results & 17 & 16 & 14 & 15 & 15 & 15 \\
HR & 9 & 7 & 7 & 8 & 8 & 8 \\
LR & 7 & 8 & 7 & 7 & 7 & 7 \\
HR subset & 5 & 5 & 4 & 5 & 5 & 5 \\
Median, W/m & & & & & & \\
All results & -5.5 & 17.9 & 3.3 & 11.4 & 4.6 & 57.9 \\
HR & -9.7 & 17.3 & 3.4 & 13.0 & 6.7 & 63.1 \\
LR & -3.0 & 17.7 & 3.3 & -2.3 & 4.6 & 46.9 \\
HR subset & -16.4 & 17.3 & 2.9 & 14.5 & 6.8 & 66.4 \\
Range, W/m & & & & & & \\
All results & 83 & 45 & 10 & 114 & 21 & 74 \\
HR & 66 & 41 & 5 & 47 & 4 & 60 \\
LR & 54 & 24 & 10 & 114 & 21 & 73 \\
HR subset & 12 & 15 & 2 & 12 & 3 & 19 \\
rms Difference, W/m & \\
All results & & & & & & \\
HR & 19 & 11 & 2 & 36 & 5 & 26 \\
LR & 21 & 16 & 2 & 16 & 2 & 24 \\
HR subset & 20 & 7 & 3 & 47 & 8 & 28 \\
\hline
\end{tabular}

For each case, the reference is case 31 . HR and $L R$ are for highand low-resolution codes, respectively.

atically from the rest of the group. Table 11 distinguishes a subset of five HR codes (HR subset) which are also identified in Figure 4 for the molecular scattering cases. (The results of one of these models was not available for case 46.) These codes differ in their vertical and spectral resolution (from 26 to 208 spectral intervals) and in their methods of solution of the radiative transfer equation. As a consequence of the use of different water vapor parameterizations, their results differ significantly for the purely absorbing cases; however, as Figure 4 and Table 11 show, the changes induced by either molecular or cloud extinction do agree fairly well.

By comparison, the $L R$ codes present a much more uniform dispersion, and it is not possible to identify any comparable subset of models as in the case of the HR codes. Since all the participating codes except one include an explicit treatment of the multiple scattering in the cloudy layer, the discrepancies can be attributed to the spectral averaging of the scattering phase functions and singlescattering albedo (note that the optical thicknesses were prespecified).

Most codes made use of approximate methods of solution of the radiative transfer equation such as the deltaEddington or delta-two-stream method, for which the scattering phase function is represented by the asymmetry factor $g$. The spectral variation of this parameter over the solar spectrum is small, and in addition, its influence on cloud radiative properties is the smallest among the various cloud optical parameters [see Slingo and Schrecker, 1982]; the problem is thus clearly that of the sharp spectral variation in the single-scattering albedo. This problem is made difficult for the $L R$ radiation codes, where the choice of a single or two spectrally averaged values may lead to large errors in the calculation of the cloud layer absorption through an erroneous treatment of the overlap between the nearinfrared cloud drop extinction and molecular absorption.
Parameterizations of this quantity, such as those proposed by Stephens [1978] or Fouquart [1986], may help to reduce the errors.

\subsection{Benchmark Solutions}

The need for benchmark solutions in cloudy conditions and the availability of powerful computers have prompted the first LBL solar radiative computations for scatteringabsorbing atmospheres. However, costs for carrying out the calculations over the entire spectrum are extreme $(\approx 100$ hours on the GFDL Cyber 205), even for scatterers confined to just one layer. Therefore Rayleigh scattering has not been considered so far, and the surface albedo has been assumed to be zero in order to avoid the multiple reflections between the surface and the cloud layer. (To facilitate further studies and comparisons with other HR codes, including other LBL models, the computations have also been performed on two limited frequency intervals: $7300-7400$ and $10,500-11,000$ $\mathrm{cm}^{-1}$. The details of these cases and the results of the LBL calculations can be obtained upon request to $\mathrm{V}$. Ramaswamy at GFDL. The results in the $10,500-11,000 \mathrm{~cm}^{-1}$ interval have been computed by the groups at GFDL and NASA GSFC; both groups have obtained identical results.)

Over the entire spectrum, 0-33,333 $\mathrm{cm}^{-1}$ (the upper limit represents $\mathrm{O}_{3} \mathrm{UV}$ absorption cutoff), the calculations have been performed both with the delta-Eddington and the "exact" method for the radiative transfer equation [ $R a$ maswamy and Freidenreich, this issue]. The absorption spectra are generated at each frequency point and in each layer, using the algorithm employed by Schwarzkopf and Fels [this issue] for the ICRCCM longwave "benchmark" calculations and which utilizes the AFGL [McClatchey et al., 1973] catalog of the molecular line parameters. There are $2.8 \times 10^{6}$ frequency points between 1 and $18,000 \mathrm{~cm}^{-1}$, over which the radiative transfer has to be performed for the scattering-absorbing atmosphere. This corresponds to a step size of $\sim 6 \times 10^{-3} \mathrm{~cm}^{-1}$ on average. This is to be contrasted with wider intervals (1-20 $\mathrm{cm}^{-1}$ typically) employed in narrow-band models. For the frequency interval between 18,000 and $33,333 \mathrm{~cm}^{-1}$, since only the radiative transfer through clouds has to be considered, and as cloud properties remain constant over broad frequency regimes, the equation of transfer has been solved for only a limited number (11) of discrete frequency points.

For the benchmark or the exact solution, the computation of radiative properties in any layer at any frequency consists in using the doubling-adding technique as described by Hunt and Grant [1969] and Wiscombe [1976]. Thirty-two streams have been used for purposes of this study. Single-scattering properties (extinction coefficient, single-scattering albedo, and asymmetry factor) at each frequency are prescribed according to the ICRCCM CL cloud specifications. The asymmetry factor is used to obtain the Henyey-Greenstein phase function, which is then expanded into a 64-term Legendre polynomial series to represent anisotropic scattering by the liquid drops at each frequency.

Whether it be the entire spectrum or limited frequency intervals, comparisons have been made in all instances between the doubling-adding calculations and those obtained using the delta-Eddington approximation, at each discrete frequency point.

Downward and upward fluxes over every $1 \mathrm{~cm}^{-1}$ interval 


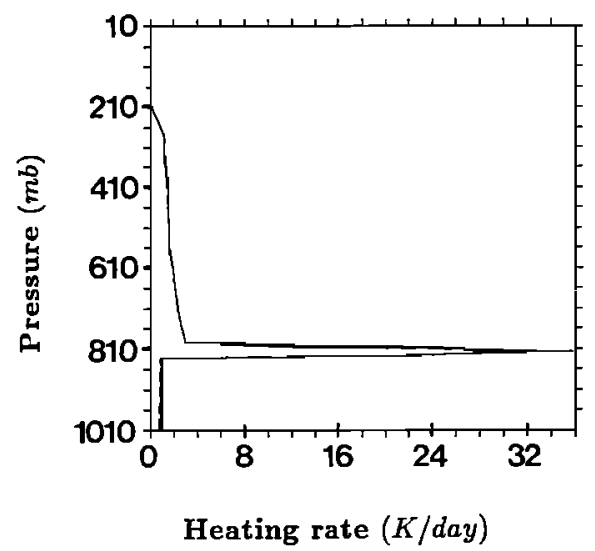

Fig. 5a. Vertical profile of the shortwave heating rate as calculated by an LBL model for a mid-latitude summer atmosphere (solar zenith angle $30^{\circ}$ ) with water vapor absorption and cloud (optical thickness $\delta=9.7$ between 800 and 820 mbar) extinction. The multiple scattering is calculated by the doubling-adding (dashed line) and the delta-Eddington (solid line) method, respectively.

have been saved for each case described above, both for the doubling-adding and for the delta-Eddington methods. Only the results from the calculations for the entire spectrum are discussed below. The cloud is located in the layer between 800 and 820 mbar. The vertical profiles of the total heating rate, as obtained by the two methods, are shown in Figure $5 a$, while the relative error for the delta-Eddington results is shown in Figure $5 b$. The largest errors are for the layers directly beneath the cloud although, from Figure $5 a$, the absolute differences are small $(<0.14 \mathrm{~K} / \mathrm{d})$. In the cloud layer the heating as given by the approximate scattering technique is in good agreement with the exact method, both for the individual frequency bands (not shown here) and for the entire spectrum.

This is a surprising result, since the delta-Eddington is known to be of poor accuracy for single-scattering albedos well below unity; these are the spectral regimes where absorption is the strongest but also where the solar irradiance is weakest. Since water vapor, too, absorbs at frequencies where droplet absorption occurs, it is possible that most of the radiation in the strongly absorbing regions is depleted above the cloud top, so that the absorption in the cloud layer

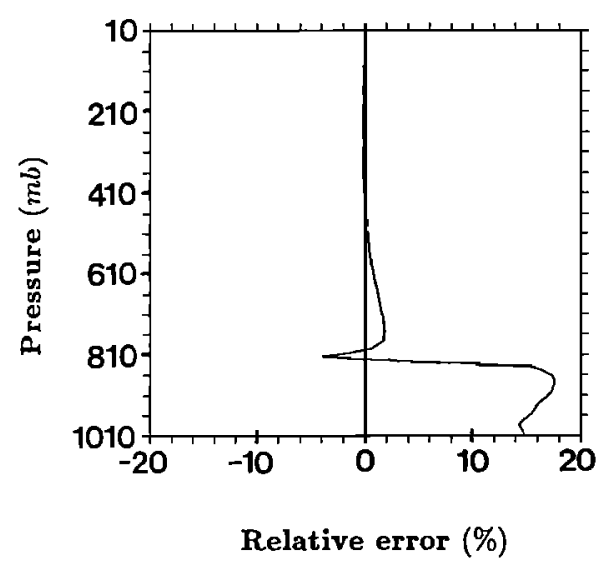

Fig. $5 b$. Vertical profile of the differences between the shortwave heating rates presented in Figure $5 a$.
TABLE 12. Reflected Solar Flux at the Top of the Atmosphere, Downward Solar Flux at the Surface, and Heating Rate in the Presence of a CL Cloud in a Mid-Latitude Summer Atmosphere With Water Vapor

\begin{tabular}{lrcc}
\hline & $\begin{array}{c}\text { Reflected } \\
\text { Flux } \\
\mathrm{W} / \mathrm{m}^{2}\end{array}$ & $\begin{array}{c}\text { Flux at } \\
\text { Surface, } \\
\mathrm{W} / \mathrm{m}^{2}\end{array}$ & $\begin{array}{c}\text { Heating in } \\
\text { Cloud, } \\
\mathrm{K} / \mathrm{d}\end{array}$ \\
\hline \multicolumn{4}{c}{$=30^{\circ}$} \\
$\boldsymbol{\theta}_{0}$ & & \\
LBL and doubling-adding & 424.1 & 499.4 & 37.4 \\
LBL and delta-Eddington & 418.6 & 504.3 & 35.9 \\
Narrow-band model & 432.8 & 513.5 & 34.3 \\
& $\boldsymbol{\theta}_{0}=75.7$ & & \\
LBL and doubling-adding & 182.0 & 78.3 & 7.2 \\
LBL and delta-Eddington & 173.8 & 86.9 & 7.4 \\
Narrow-band model & 181.7 & 85.6 & 6.8 \\
\hline
\end{tabular}

Cloud is located between 800 and 820 mbar. Solar zenith angles are $30^{\circ}$ and $75.7^{\circ}$. Values are listed for line-by-line computations employing the "exact" (doubling-adding) and the approximate (delta-Eddington) technique and a narrow-band model (see text).

is dominated by the drops [Ramaswamy and Freidenreich, this issue]. Then, droplet absorption for a low lying cloud would occur only in the moderate to weakly absorbing frequencies where the delta-Eddington results are not as severely degraded. Because the contribution by the different spectral regions to the total cloud heating is weighted by the spectral irradiance at cloud top, this would diminish the magnitude of the net discrepancy when the entire spectrum is considered. Yet another explanation is the possibility of error compensations occurring throughout the spectrum. The speculations can be resolved only by further calculations, accompanied by detailed analyses.

\subsection{Narrow-Band Versus LBL Results}

Table 12 compares the reflected fluxes at the top of the atmosphere, the fluxes at the surface, and the heating rates within the cloud layer, for the LBL calculations either with the doubling-adding or the delta-Eddington method and for a narrow-band model. The narrow-band model has a coarser spectral resolution than the LBL model above but has a finer resolution than the wideband or LR codes. It has 208 spectral intervals and is based upon the practically improved flux method [Zdunkowski et al., 1980]; the water vapor absorption is approximated in each frequency interval by a sum of exponentials. This model has participated in the ICRCCM study; the comparisons in Table 12 may thus give an estimate of the agreement between the HR codes and the benchmark calculations.

If we compare the two LBL calculations, Table 12 shows that, for $\theta_{0}=30^{\circ}$, the relative errors with the deltaEddington calculations remain less than $2 \%$ for the fluxes and $4 \%$ for the cloud layer heating rate. For the low solar elevation, errors increase to $11 \%$ for the flux at the surface; smaller $(\leq 4 \%)$ relative errors occur for the reflected flux at the top of the atmosphere and for the heating rate in the cloud. With the narrow-band model these errors do not increase significantly, and indeed, compensations may occur, leading to a better accuracy of the surface fluxes in the band model.

Further research is in progress for clouds with different optical depths and located at different altitudes. At present, our results indicate that, for clouds with large optical depths, 
TABLE 13. Same as Table 9 but for Aerosol Scattering Conditions

\begin{tabular}{|c|c|c|c|c|c|c|c|c|c|c|}
\hline \multirow[b]{2}{*}{ Case } & \multirow[b]{2}{*}{$\begin{array}{c}\text { Aerosol } \\
\text { Profile }\end{array}$} & \multirow[b]{2}{*}{$\begin{array}{c}\text { Zenith } \\
\text { Angle, deg }\end{array}$} & \multirow[b]{2}{*}{$\begin{array}{l}\text { Surface } \\
\text { Albedo }\end{array}$} & \multirow[b]{2}{*}{$\begin{array}{l}\text { No. of } \\
\text { Models }\end{array}$} & \multicolumn{3}{|c|}{ Downward Flux at the Surface } & \multicolumn{3}{|c|}{ Total Atmospheric Absorption } \\
\hline & & & & & $\begin{array}{l}\text { Median, } \\
\mathrm{W} / \mathrm{m}^{2}\end{array}$ & $\begin{array}{l}\text { Range, } \\
\%\end{array}$ & $\begin{array}{c}\text { rms } \\
\text { Difference, \% }\end{array}$ & $\begin{array}{l}\text { Median, } \\
\mathrm{W} / \mathrm{m}^{2}\end{array}$ & $\underset{\%}{\text { Range, }}$ & $\begin{array}{c}\text { rms } \\
\text { Difference, \% }\end{array}$ \\
\hline 50 & MAR-I & 30 & 0.2 & 10 & 936.2 & 4 & 1 & 214.7 & 16 & 5 \\
\hline 51 & MAR-I & 30 & 0.8 & 10 & 985.7 & 4 & 2 & 252.5 & 15 & 5 \\
\hline 52 & MAR-I & 75 & 0.2 & 10 & 223.8 & 7 & 2 & 88.4 & 11 & 4 \\
\hline 53 & MAR-I & 75 & 0.8 & 10 & 234.5 & 8 & 3 & 95.0 & 13 & 5 \\
\hline 54 & MAR-II & 30 & 0.2 & $\begin{array}{l}10 \\
(8)\end{array}$ & 444.4 & $\begin{array}{c}61 \\
(23)\end{array}$ & $\begin{array}{c}18 \\
(10)\end{array}$ & 601.2 & $\begin{array}{c}46 \\
(18)\end{array}$ & $\begin{array}{l}13 \\
(7)\end{array}$ \\
\hline 55 & MAR-II & 30 & 0.8 & $\begin{array}{l}10 \\
(8)\end{array}$ & 511.0 & $\begin{array}{l}70 \\
(23)\end{array}$ & $\begin{array}{l}18 \\
(8)\end{array}$ & 739.1 & $\begin{array}{l}32 \\
(16)\end{array}$ & $\begin{array}{l}10 \\
(6)\end{array}$ \\
\hline 56 & MAR-II & 75 & 0.2 & $\begin{array}{l}10 \\
(8)\end{array}$ & 58.8 & $\begin{array}{c}70 \\
(37)\end{array}$ & $\begin{array}{c}21 \\
(16)\end{array}$ & 190.1 & $\begin{array}{c}32 \\
(20)\end{array}$ & $\begin{array}{l}11 \\
(8)\end{array}$ \\
\hline 57 & MAR-II & 75 & 0.8 & $\begin{array}{l}10 \\
(8)\end{array}$ & 67.5 & $\begin{array}{c}63 \\
(39)\end{array}$ & $\begin{array}{l}20 \\
(15)\end{array}$ & 209.0 & $\begin{array}{c}29 \\
(18)\end{array}$ & $\begin{array}{l}10 \\
\text { (7) }\end{array}$ \\
\hline
\end{tabular}

the LBL computations using the delta-Eddington approximation can be in reasonable agreement with those obtained using the exact method (doubling-adding); they also show that the same accuracy can be obtained with much cheaper but still HR radiation codes. A more general conclusion will have to await the computational results from further case studies.

\section{Aerosols}

Eight cases were included to test the ability of radiation codes to account for aerosol radiative effects. The atmospheric profile was that at mid-latitude summer, the solar zenith angles were again $30^{\circ}$ and $75^{\circ}$, and the surface albedos 0.2 and 0.8 . Two maritime aerosol profiles were considered; their radiative properties and vertical mass loading were those of the MAR-I and MAR-II of the Standard Atmospheres [World Climate Research Programme, 1983]. The total aerosol optical thicknesses at $\lambda=0.55 \mu \mathrm{m}$ were $\delta_{a}=$ 0.09 and 3.065 , respectively. In addition, it must be noted that the absorption of the continental aerosols, which are the main constituents of the MAR-II profile, is large $(\omega=0.89$ compared to 0.99 for the maritime ones).

The summary of the results of the aerosol cases (50-57) are presented in Table 13. These results should be compared with those of cases 31-34 (i.e., mid-latitude atmosphere) of Table 9. Only 10 models participated in this particular exercise; among these were only three GCM-type radiation codes, emphasizing the fact that aerosols are only occasionally accounted for in GCMs. This makes the comparison much less instructive, but nevertheless illustrates the present state-of-the-art in the modeling of aerosol radiative transfer for climate studies. Aerosols may have an important impact on such key quantities as the surface radiation fluxes and the diabatic heating of the atmosphere. They may also have a considerable effect on the derivation of shortwave surface fluxes from satellite observations. From a more computational point of view, it is interesting to estimate the sensitivity of the radiation codes under comparison, to the relatively small optical thicknesses added in the model layers.

There is no substantial degradation in the results for the MAR-I aerosol profile; the reduction of the number of participants results in a strong decrease of the range and rms differences. This is definitely not the case for the MAR-II, where the rms difference is $18-21 \%$ for the downward flux at the surface. These are the largest rms errors observed in the entire comparison. A closer examination of the individual results shows that, in this case, two HR models (including one of the HR subset) strongly disagree with the others. The discrepancy is as large as $\mathbf{5 0 \%}$ in the downward flux at the surface. The other models show a more reasonable agreement (see the results within parentheses). However, the number of remaining models is small, and this casts some doubt on the representativeness of this particular comparison.

\section{Discussions AND CONCLUSIONS}

Just as for the longwave clear-sky case [Luther et al., 1988], the intercomparison of the shortwave radiation codes has revealed a considerable spread in the responses of different codes to a set of well-defined atmospheric profiles. An outstanding feature of the intercomparison exercise has been the larger relative errors to be found in the atmospheric absorbed fluxes than in the surface fluxes. This is due to absorption being a smaller residual of the difference between large numbers (viz., fluxes). This is a significant point to be noted, since absorbed fluxes are a primary component of the diabatic heating rate in the atmosphere.

Substantial discrepancies occur even for the simplest case of pure water vapor absorption, with rms difference of $1 \%$ or $3 \%\left(\sim 10 \mathrm{~W} / \mathrm{m}^{2}\right.$ for the two solar elevations considered, $30^{\circ}$ and $75^{\circ}$ ) for the downward flux at the surface and $6-11 \%$ for the total atmospheric absorption. For $F_{S}^{\downarrow}$ the rms differences increase to nearly $4 \%\left(\sim 10 \mathrm{~W} / \mathrm{m}^{2}\right)$ at low solar elevations, when all absorbers are considered and the molecular scattering is included. In cloudy conditions they amount to between $4 \%$ and $10 \%\left(50 \mathrm{~W} / \mathrm{m}^{2}\right)$, depending on the cloud optical thickness, the worst results being obtained for the thickest cloud. With aerosols, the discrepancies increase from $18 \%$ to $21 \%\left(90 \mathrm{~W} / \mathrm{m}^{2}\right)$ for large aerosol loadings. The total ranges are very large, from $4 \%$ for the pure water vapor cases, up to $40 \%$ for the thick cloud cases, and $70 \%$ for the high aerosol loading cases. This spread has many causes; among them are misunderstandings of the instructions, although several iterations have been performed between the participants, reducing the probability of such events. This has indeed led to a significant narrowing of the initial spread. In the end, some codes yielded results that were at the extreme end of the range. Since we not only compared the fluxes and atmospheric absorption but also the changes induced on these quantities when a new physical process is included in the calculations, we eliminated the 
possibility of error propagation. Consequently, systematic differences generally occur only for a particular subset of comparisons, such as the effect of scattering by molecules, clouds, or aerosols. They can thus be related to deficiencies in the treatment of the particular physical process.

The findings here must be put in perspective with the energetics involved in climate processes. According to the Earth Radiation Budget Experiment [Ramanathan et al., $1989 a, b]$, the planetary averaged cloud radiation forcing is close to $-15 \mathrm{~W} / \mathrm{m}^{2}$, the anomalies in outgoing shortwave radiation associated with an El Niño event are of the order of $80 \mathrm{~W} / \mathrm{m}^{2}$ [Ardanuy and Kyle, 1986], and a significant climate change might result from a mere $4 \mathrm{~W} / \mathrm{m}^{2}$ increase of the net flux at the tropopause due to doubling of the atmospheric $\mathrm{CO}_{2}$ concentration.

Indeed, most climate research since the Global Atmospheric Research Program (GARP) [Global Atmospheric Programme, 1975], and more recently, the World Climate Research Programme [1984], have stressed the need for accuracies of the order of $10 \mathrm{~W} / \mathrm{m}^{2}$ in the monthly mean surface downward radiation flux and $0.05 \mathrm{~K} / \mathrm{d}$ for tropospheric heating rates. This last requirement corresponds to $\sim 5 \mathrm{~W} / \mathrm{m}^{2}$ in the total tropospheric absorption. According to the results of the ICRCCM exercise, much larger errors may result from the solar radiation calculations alone.

The present study has identified two main causes of uncertainty in the computation of the shortwave fluxes.

1. The calculation of the water vapor absorption, a primary component of the clear-sky radiative interaction, is critical, and different parameterizations may lead to significant differences between band model results, independent of their spectral resolution. In particular, it has been shown that the parameterizations based upon the LOWTRAN code differ systematically from those based upon LBL or randomband models using the AFGL spectral data bank. These differences increase with the water vapor paths and, in terms of surface fluxes, they may amount to $1.5 \%\left(\simeq 15 \mathrm{~W} \mathrm{~m}^{-2}\right)$ to $4 \%\left(\simeq 9 \mathrm{~W} \mathrm{~m}^{-2}\right)$ in a tropical atmosphere, depending on the solar elevation. These biases are significant, considering the accuracy typically required for surface fluxes $\left(10 \mathrm{~W} / \mathrm{m}^{2}\right.$ for the TOGA program). While rigorous reference solutions for radiative transfer in the atmosphere can be obtained from LBL computations performed on a precise theoretical basis, it is important to remember that fundamental inadequacies could be associated with details of the spectral lines and/or irradiances at the top of the atmosphere. Thus the most definitive tests of the radiation algorithms will come only through comparisons of these HR calculations with carefully designed experiments, such as the Spectral Radiation Experiment (SPECTRE) proposed in the context of the First International Satellite Cloud Climatology Project (ISCCP) regional experiments, and/or laboratory measurements.

2 . The interactions between multiple scattering and molecular absorption are particularly difficult to handle adequately with low spectral resolution codes. This is the cause of the strong increase of both rms differences and ranges among the various models when molecular scattering is added or when the atmospheric profiles include aerosols or a cloudy layer. In the first case the main problem is the choice of the spectrally averaged Rayleigh optical thickness $\delta_{R}$; for cloudy conditions the problem arises with respect to both the optical thickness $\delta$ and the single-scattering albedo $\omega$, both of which exhibit a spectral variation. In this study, $\delta$ was specified, and only the spectral variation in the second parameter was considered; this varies sharply with frequency in the near infrared. In the present set of results the problem of specifying $\omega$ led to quite significant deviations in the results of some low spectral resolution radiation codes from those having a high resolution. In fact, for the cloud cases involving typical liquid water contents $\left(200 \mathrm{~g} / \mathrm{m}^{2}\right.$; optical depth 9.7), the ranges in model values and the rms differences are very large.

Besides emphasizing the large dispersion of the results reported here, more optimistic conclusions can be drawn from a closer examination of the individual results.

1. The large range in the results of the high spectral resolution codes is due to a few models which differ systematically from the rest. If we choose to ignore the models yielding the extreme values in the range, it is found that, despite the fact that the remaining codes can be based upon very different basic parameterizations or approximations, their results agree fairly well with each other. If the initial discrepancies attributable to the use of various water vapor transmissions are removed, the overall agreement in $F_{S}$ is better than $1 \%$ for all cases, except the high aerosol loading ones.

2. Providing that the Rayleigh optical thickness is adequately parameterized, codes developed for climate models (low spectral resolution) appear to simulate clear-sky shortwave fluxes in reasonable correspondence to the results from the high-resolution codes.

Most of the conclusions drawn for the longwave clear-sky comparisons [Luther et al., 1988] still apply for the shortwave ones. In particular, many radiation algorithms could have inherently unknown errors that may significantly affect the conclusions of the studies in which they are used. This is true for climate modeling and weather forecasting studies as well as for other applications, such as inferences from satellite observations.

To a large extent, the present intercomparison exercise has conducted a detailed analyses of primarily the clear-sky cases (i.e., molecular absorption and scattering). In fact, in view of the divergences manifested between the models even for the simple case of water vapor absorption only, it became necessary to examine this issue in considerable detail here. The reasons for the divergences between the various models, besides being one of spectral resolution, need to be explored further, beyond the limited number of case studies performed thus far. It is emphasized that more definitive recommendations concerning optimal procedures to calculate the transfer of solar radiation in scattering-absorbing inhomogeneous atmospheres will emerge only from comparisons of very detailed computations with high precision observations (laboratory and field). (Plans regarding the latter set of activities are already underway.)

In the future, the ICRCCM data bank will be maintained, made available upon request on PC compatible disks, and be regularly updated. As was the case for the longwave results, we recommend that the ICRCCM shortwave cases, too, be used to test radiation algorithms prior to their application.

Acknowledgments. The ICRCCM study would have been impossible without the enthusiasm of all individual participants who spent a great deal of time without compensation. This work is indeed that of all of them listed in Table 2. In addition, we gratefully acknowledge the support of $F$. Luther, who helped initiate this part 
of the study; since his untimely death, R. Ellingson, as a cochairman, was very effective in persuading additional scientists to join the ICRCCM group. Jim Ellis helped us on many occasions, and it is a pleasure to thank him here. Suggestions given by S. Fels, before his sudden demise, were strongly instrumental in enhancing the clarity of the manuscript. The paper also benefited considerably from the comments of two anonymous reviewers. We thank $S$. M. Friedenreich for assistance with the LBL computations and J. Kennedy for typing the manuscript. This work has been supported, in part, by the CNRS through the Programme National d'Etudes de la Dynamique du Climat.

\section{REFERENCES}

Ackerman, M., Ultraviolet solar radiation related to mesospheric processes, in Mesospheric Models and Related Experiments, edited by G. Fiocco, D. Reidel, Hingham, Mass., 1971.

Ardanuy, P. E., and H. L. Kyle, El Niño and outgoing longwave radiation: Observations from Nimbus 7 ERB, Mon. Weather Rev., 114, 415-433, 1986.

Curtis, A. R., Discussion of "A statistical model for water vapor absorption," by R. M. Goody, Q. J. R. Meteorol. Soc., 78, 638, 1952.

Elsasser, W. M., Heat transfer by infrared radiation in the atmosphere, Harvard Meteorol. Stud. 6, 43 pp., Harvard University Press, Cambridge, Mass., 1942.

Fels, S. B., Simple strategies for inclusion of Voigt effects in infrared cooling rate calculations, Appl. Opt., 18, 2634-2637, 1979.

Fouquart, Y., Radiative transfer in climate modeling, paper presented at the meeting on Physically Based Modeling and Simulation of Climate and Climatic Change, NATO Adv. Stud. Inst., Erice, Sicily, May 11-23, 1986.

Fouquart, Y., and B. Bonnel, Computations of solar heating of the Earth's atmosphere: A new parameterization, Beitr. Phys. Atmos., 53, 35-62, 1980.

Geleyn, J.-F., and A. Hollingsworth, An economical analytical method for the computation of the interaction between scattering and line absorption of radiation, Beitr. Phys. Atmos., 52, 1-16, 1979.

Global Atmospheric Programme, The physical basis of climate and climate modeling, Report of the international Study Conference, GARP Publ. Ser. 16, 265 pp., World Meteorol. Organ., Geneva, 1975.

Godson, W. L., Spectral models and the properties of transmission functions, paper presented at the Toronto Meteorology Conference, R. Meteor. Soc., Berkshire, England, 1953.

Harshvardhan, R. Davies, D. A. Randall, and T. G. Corsetti, A fast radiation parameterization for atmospheric circulation models, $J$. Geophys. Res., 92, 1009-1016, 1987.

Hense, A., M. Kerchgens, and E. Rashke, An economical method for computing the radiative energy transfer in circulation models, Q. J. R. Meteorol. Soc., 108, 231-252, 1982.

Herman, G. F., and J. A. Curry, Observational and theoretical studies of solar radiation in Arctic stratus clouds, J. Clim. Appl. Meteorol., 23, 5-24, 1984.

Hunt, G. E., and I. P. Grant, Discrete space theory of radiative transfer and its application to problems in planetary atmospheres, J. Atmos. Sci., 26, 963-972, 1969.

Inn, E. C. Y., and Y. Tanaka, Absorption coefficient of ozone in the ultraviolet and visible regions, J. Opt. Soc. Am., 43, 870-873, 1953.

Kiehl, J. T., and V. Ramanathan, $\mathrm{CO}_{2}$ radiative parameterization used in climate models: Comparison with narrow-band models and with laboratory data, J. Geophys. Res., 88, 5191-5202, 1983.

Labs, D., and H. Neckel, Transformation of the absolute solar radiation data into the international practical temperature scale of 1968, Solar Phys. 15, 79-87, 1970.

Lacis, A. A., and J. E. Hansen, A parameterization for the absorption of solar radiation in the Earth's atmosphere, J. Atmos. Sci., 31, 118-132, 1974.

Luther, F. M., R. G. Ellingson, Y. Fouquart, S. B. Fels, N. A. Scott, and W. J. Wiscombe, Intercomparison of radiation codes in climate models (ICRCCM): Longwave clear-sky results, A workshop summary, Bull. Am. Meteorol. Soc., 69, 40-48, 1988.

Malkmus, W., Random Lorentz band models with exponential tailed $S^{-1}$ line intensity distribution function, J. Opt. Soc. Am., $57,323-329,1967$.
Manabe, S., and R. F. Strickler, Thermal equilibrium of the atmosphere with a convective adjustment, J. Atmos. Sci., 21, 361-387, 1964.

McClatchey, R. A., R. W. Fenn, J. E. A. Selby, F. E. Volz, and J. S. Garing, Optical properties of the atmosphere, 3rd ed., 110 pp., Environ. Res. Pap. 411, Air Force Cambridge Res. Lab., Bedford, Mass., 1972.

McClatchey, R. A., W. S. Benedict, S. A. Clough, D. E. Burch, R. F. Calfee, K. Fox, L. S. Rothman, and J. S. Garing, AFCRL atmospheric absorption line parameters compilation, Rep. AFCRL-TR-73-0096, 83 pp., Hanscom Air Force Base, Bedford, Mass., 1973.

Neckel, H., and D. Labs, The solar radiation between 3300 and 23500 Å, Solar Phys., 90, 205-258, 1984.

Ramanathan, V., R. D. Cess, E. F. Harrison, P. Minnis, B. R. Barkstrom, E. Ahmad, and D. Hartmann, Cloud-radiative forcing and climate: Results from the Earth radiation budget experiment, Science, 243, 1-140, 1989a.

Ramanathan, V., B. R. Barkstrom, and E. F. Harrison, Climate and the Earth's radiation budget, Phys. Today, 42(5), 22-32, 1989 b.

Ramaswamy, V., and S. M. Freidenreich, Solar radiative lineby-line determination of water vapor absorption and water cloud extinction in inhomogeneous atmospheres, J. Geophys. Res., this issue.

Rothman, L. S., R. R. Gamache, A. Barbe, A. Goldman, J. R. Gillis, L. R. Brown, R. A. Toth, J. M. Flaud, and C. Camy-Perot, AFGL atmospheric absorption line parameter computations: 1982 edition, Appl. Opt., 22, 2247-2256, 1983.

Schwarzkopf, M. D., and S. B. Fels, The simplified exchange method revisited: An accurate, rapid method for computation of infrared cooling rates and fluxes, J. Geophys. Res., this issue.

Selby, J. E. A., F. X. Kneizys, J. H. Chetwynd, Jr., and R. A. McClatchey, Atmospheric transmittance/radiance: Computer code LOWTRAN 4, Environ. Res. Pap. N3 587, 79 pp., Air Force Geophys. Lab., Bedford, Mass., 1978.

Slingo, A., and H. M. Schrecker, On the shortwave radiative properties of stratiform water clouds, $Q . J . R$. Meteorol. Soc., $108,407-426,1982$.

Stephens, G. L., Radiation profiles in extended water clouds, II, Parameterization schemes, J. Atmos. Sci., 35, 2123-2132, 1978.

Stephens, G. L., Optical properties of eight water cloud types, Div. Atmos. Phys. Tech. Pap. Austo. CSIRO, no. 36, 1-35, 1979.

Stephens, G. L., The parameterization of radiation for numerical weather prediction and climate model, Mon. Weather Rev., 112, 826-867, 1984.

Thekaekara, M. P., and J. Drummond, Standard values for the solar constant and its spectral components, Nature, 229, 6-9, 1971.

Vigroux, E., Contribution à l'étude expérimentale de l'absorption de l'ozone, Ann. Phys., 8, 709-762, 1953.

Wiscombe, W. J., On initialization, error and flux conservation in the doubling method, J. Quant. Spectrosc. Radiat. Transfer, I6, 637-658, 1976.

World Climate Research Programme, Report of the expert meeting on aerosols and their climatic effects, Rep. WCP 55, 107 pp., World Meteorol. Organ., Geneva, 1983.

World Climate Research Programme, Scientific plan, Report of the WMO ICSU Joint Scientific Committee, WCRP Publ. Ser. 2, 95 pp., World Meteorol. Organ., Geneva, 1984.

Yamamoto, G., Direct absorption of solar radiation by atmospheric water vapor, J. Atmos. Sci., 19, 182-188, 1962.

Zdunkowski, W. G., R. M. Welch, and G. Korb, An investigation of the structure of typical two-stream methods for the calculation of solar fluxes and heating rates in clouds, Beitr. Phys. Atmos., 53, 147-166, 1980.

Zdunkowski, W. G., W.-G. Panhans, R. R. Welch, and G. J. Korb, A radiation scheme for circulation and climate models, Beitr. Phys. Atmos., 55, 215-238, 1982.

B. Bonnel and Y. Fouquart, Laboratoire d'Optique Atmospherique, 59655 Villeneuve d'Ascq, France.

V. Ramaswamy, NOAA Geophysical Fluid Dynamics Laboratory, P. O. 308, Princeton University, Princeton, NJ 08542.

(Received May 5, 1989; revised January 13, 1990; accepted January 24, 1990.) 